\title{
Interprofessional Stroke Rehabilitation for Stroke Survivors Using Home Care
}

\author{
Maureen Markle-Reid, Camille Orridge, Robin Weir, Gina Browne, Amiram \\ Gafni, Mary Lewis, Marian Walsh, Charissa Levy, Stacey Daub, Heather Brien, \\ Jacqueline Roberts, Lehana Thabane
}

\begin{abstract}
Objective: To compare a specialized interprofessional team approach to community-based stroke rehabilitation with usual home care for stroke survivors using home care services. Methods: Randomized controlled trial of 101 community-living stroke survivors ( $<18$ months post-stroke) using home care services. Subjects were randomized to intervention $(n=52)$ or control $(n=49)$ groups. The intervention was a 12-month specialized, evidence-based rehabilitation strategy involving an interprofessional team. The primary outcome was change in health-related quality of life and functioning (SF-36) from baseline to 12 months. Secondary outcomes were number of strokes during the 12-month follow-up, and changes in community reintegration (RNLI), perceived social support (PRQ85Part 2), anxiety and depressive symptoms (Kessler-10), cognitive function (SPMSQ), and costs of use of health services from baseline to 12 months. Results: A total of 82 subjects completed the 12-month follow-up. Compared with the usual care group, stroke survivors in the intervention group showed clinically important (although not statistically significant) greater improvements from baseline in mean SF-36 physical functioning score $(5.87,95 \% \mathrm{CI}-3.98$ to $15.7 ; \mathrm{p}=0.24)$ and social functioning score $(9.03, \mathrm{CI}-7.50$ to 25.6 ; $\mathrm{p}=0.28)$. The groups did not differ for any of the secondary effectiveness outcomes. There was a higher total per-person costs of use of health services in the intervention group compared to usual home care although the difference was not statistically significant $(\mathrm{p}=0.76)$. Conclusions: A 12-month specialized, interprofessional team is a feasible and acceptable approach to community-based stroke rehabilitation that produced greater improvements in quality of life compared to usual home care. Clinicaltrials.gov identifier: NCT00463229
\end{abstract}

RÉSUMÉ: Réadaptation interprofessionnelle à domicile suite à un accident vasculaire cérébral. Objectif : Le but de notre étude était de comparer une approche utilisant une équipe interprofessionnelle spécialisée pour la réadaptation communautaire au moyen de services à domicile, suite à un accident vasculaire cérébral (AVC). Méthode: Nous avons effectué un essai contrôlé randomisé chez 101 patients ayant subi un AVC moins de 18 mois auparavant, qui vivaient dans la communauté et utilisaient des services de soins à domicile. Les sujets ont été randomisés au groupe intervention (n = 52) ou au groupe témoin $(\mathrm{n}=49)$. L'intervention consistait à appliquer, par une équipe interprofessionnelle, une stratégie spécialisée de réadaptation basée sur des preuves pendant 12 mois. Le critère d'évaluation principal était le changement de la qualité de vie reliée à la santé et au fonctionnement (SF-36) au début et après 12 mois. Les critères d'évaluation secondaires étaient le nombre d'AVC au cours des 12 mois du suivi et les changements dans la réintégration dans la communauté (RNLI), le soutien social perçu (PRQ85-part2), les symptômes d'anxiété et de dépression (Kessler-10), la fonction cognitive (SPMSQ) et les coûts d'utilisation des services de santé au cours des 12 mois de l'étude. Résultats : Quatre-vingt-deux sujets ont complété les 12 mois de l'étude. Une amélioration clinique importante du score moyen du fonctionnement physique à l'échelle SF-36 (5,87; IC à $95 \% 3,98$ à $15,7 ; \mathrm{p}=0,24)$, bien que non significative au point de vue statistique, et du score du fonctionnement social $(9,03 ;$ IC 7,50 à 25,$6 ; p=0,28)$ a été observée chez les sujets du groupe intervention par rapport au début de l'étude. Il n'y avait pas de différence en ce qui a trait aux critères d'évaluation secondaires. Le coût total de l'utilisation des services de santé par personne était plus élevé dans le groupe intervention comparé au groupe de soins à domicile usuels, bien que la différence n'était pas significative au point de vue statistique $(\mathrm{p}=0,76)$. Conclusions : La réadaptation dans la communauté après un AVC par une équipe interprofessionnelle spécialisée est une approche faisable et acceptable qui produit des améliorations plus importantes de la qualité de vie par rapport aux soins à domicile usuels.

Can J Neurol Sci. 2011; 38: 317-334

Although many advances have been made in stroke prevention and management, stroke continues to be a prevalent and burdensome condition, particularly among older adults ${ }^{1}$. Stroke is the leading cause of adult disability and the third leading cause of death in Canada ${ }^{2,3}$. More than 50,000 Canadians experience a stroke each year and more than 300,000 (1\% of the population) live with the ongoing effects ${ }^{4,5}$ Following a sentinel stroke, there is a $20 \%$ chance of having another stroke within two years ${ }^{6}$. The costs of health care associated with stroke are staggering. Canadians spend a total of $\$ 3$ million days per year in hospital because of the physical disability associated with stroke. The annual direct cost to the health care system is estimated to be over $\$ 2.7$ billion, and the estimate increases to $\$ 4$ billion when indirect costs are included 6 . The average acute care cost is about $\$ 27,500$ per stroke. Annual nursing home costs

From McMaster University, School of Nursing, Hamilton, Ontario, Canada.

Received January 7, 2010. Final Revisions Submitted SePtember 15, 2010. Correspondence to: Maureen Markle-Reid, McMaster University, School of Nursing, 1200 Main Street West, HSC 3N28H, Hamilton, Ontario, L8N 3Z5, Canada. 
for stroke survivors in Canada are estimated at over $\$ 600$ million ${ }^{7}$. Over the next seven years, the incidence of stroke is expected to increase by $31 \%$ with the growing elderly population and the rising prevalence of diabetes and obesity ${ }^{8}$.

Aside from the economic cost, the human cost of stroke should not be underestimated. Almost $60 \%$ of stroke survivors are left with moderate-to-severe functional impairment and many are so severely disabled that they need long-term care, placing a major burden on families and communities ${ }^{6,9}$. Up to $75 \%$ of stroke survivors require help with daily living $\operatorname{activities}^{10}$, for as long as three years post-stroke ${ }^{1,11-13}$. Systematic reviews of qualitative $\mathrm{e}^{14,15}$ and quantitative ${ }^{16,17}$ studies of the experience of stroke recovery indicate that stroke survivors have a diversity of long-standing problems, including social isolation, restricted participation in leisure activities, delayed return to work, anxiety, depression, and distress. These characteristics are associated with greater morbidity and dependency, increased use of health care resources, and death $^{18,19}$.

\section{Community-Based Stroke Rehabilitation Programs}

Reducing the burden of stroke requires optimizing stroke prevention and improving acute care, but rehabilitation is equally essential $^{20}$. Because up to $60 \%$ of stroke survivors are left with some degree of functional impairment ${ }^{1,21}$, stroke rehabilitation should be a major component of health service provision to maximize quality of life, minimize the effects of stroke, and promote community reintegration. Stroke rehabilitation is multidimensional, consisting of the combination and coordination of medical, social, educational, and vocational resources aimed at optimizing health and functional independence ${ }^{22}$. Community reintegration, as part of stroke rehabilitation, includes facilitation of psychosocial coping and adaptation for the patient and caregivers, promotion of rejoining the community and reestablishing social and family roles, and enhancement of quality of life ${ }^{7}$.

Randomized controlled trials support the effectiveness of a specialized and coordinated interprofessional team approach to stroke rehabilitation, compared to less organized care, in reducing stroke-related mortality and morbidity, length of stay, and costs of care in inpatient settings ${ }^{23-26}$. Interprofessional early supported discharge (ESD) interventions with continued rehabilitation in the early discharge phase $(<3$ months) have also been shown to reduce the length of hospital stay (on average by eight days) ${ }^{18,27-37}$, increase physical health and independence $\mathrm{e}^{28,29,38-40}$, reduce the risk of death or dependency by six patients per 100 treated $^{27}$, decrease caregiver strain ${ }^{41,42}$, increase the level of community reintegration ${ }^{28}$, and improve patient satisfaction for selected mild-to-moderately disabled stroke survivors $^{27,43}$. Canadian projections based on a recently developed economic model suggest that, over a 20 -year period, organized stroke care, including specialized units and teams and access to acute interventions, could prevent 160,000 strokes and achieve $\$ 8$ billion in net savings to the Canadian health care system $^{44}$.

Over the past decade, there has been a shift in focus from inpatient rehabilitation to community-based rehabilitation as a less expensive alternative $e^{41,45-47}$. The increasing emphasis on early discharge, which will be encouraged by this shift in locus of care, means that more recovery and rehabilitation will be taking place earlier within the home than in past decades ${ }^{48,49}$. At six months post-stroke, $80 \%$ of stroke survivors will be living at home, $83 \%$ of whom will have less than optimal recovery, requiring further rehabilitation ${ }^{50}$.

Home care occupies a strategic position in providing community-based stroke prevention and rehabilitation. Home care is defined as "an array of services for people of all ages, provided in the home and community setting, that encompasses health promotion and teaching, curative intervention, end-of-life care, rehabilitation, support and maintenance, social adaptation and integration and support for the informal (family) caregiver" 51 . It is estimated that $15-46 \%$ of stroke survivors are referred to home care services following acute hospitalization or inpatient rehabilitation ${ }^{52}$. In 2005-06, there were 17,626 stroke clients who received services from home care programs in Ontario $^{52}$. Because many of the risk factors and problems associated with stroke are preventable and require ongoing management, home care is not only viable but potentially more effective than care in an institutional setting. However, the characteristics of stroke survivors using home care services in Canada are not well documented. As well, there is little or no information about the best way to provide community-based stroke rehabilitation for this growing population. Furthermore, little is known about the effectiveness of a specialized and coordinated interprofessional team approach to communitybased stroke rehabilitation for stroke survivors using home care services and the relative costs of such services in a Canadian setting.

\section{The Evidence-Care Gap}

Many evidence-based recommendations as to how to provide optimal community-based stroke rehabilitation have been made $23,52-57$. However, a gap exists between the scientific evidence and its application in clinical practice ${ }^{58,59}$. Furthermore, no formal community-based stroke rehabilitation program directed at stroke survivors using home care services has been established as a standard of care in Canada ${ }^{60}$. This means that community-living stroke survivors may be receiving suboptimal management at best and ineffective or deleterious treatments at worst. Several groups have called for improving the transfer of evidence from randomized controlled trials into practice ${ }^{60}$. However, many challenges exist with respect to transferring knowledge regarding effective community-based stroke rehabilitation strategies into home care practice, including the need for considerable reorganization of the delivery of home care services. Specifically, home care is underfunded, the $9 \%$ yearly growth has outpaced the $2.2 \%$ increase in spending ${ }^{51,61-64}$, resulting in a shift in the allocation of scarce home care services away from prevention and rehabilitation to meet the more pressing need for post-acute care substitution ${ }^{61,65-67}$.

The result is that home care clients have limited access to professional services directed toward stroke prevention and rehabilitation and community reintegration. In 2006-07 in Ontario, the proportion of stroke survivors using professional home care services (e.g., nursing, occupational therapy, physiotherapy) ranged from $3 \%$ to $37 \%^{68}$. Follow-up care is also limited. In 2006-07 in Ontario, the median length of home care service for stroke survivors was two months ${ }^{68}$. Other barriers 
include inadequate collaboration among health care sectors (e.g., no continuity among providers) ${ }^{60,69}$, and lack of expertise among home care service providers in stroke prevention and rehabilitation strategies. A final barrier is the lack of evidencebased practice standards specific to stroke rehabilitation in home care for stroke survivors. New models of care are needed, and different solutions are required to address these barriers to enhance the ability of home care programs to provide effective stroke rehabilitation. Hence, this study was designed to determine how to optimize the allocation of health services for this population.

Based on the potentially important role of home care in stroke rehabilitation, compelling evidence for a specialized interprofessional team approach, and increasing pressure for evidence of efficient use of scarce resources, we identified the need for a randomized trial of the effectiveness and cost of a specialized interprofessional team approach to stroke rehabilitation. The rationing of home care services for clients with chronic needs allowed for a natural comparison of the effects of a proactive service with those of on-demand use of these services. Our primary hypothesis was that stroke survivors receiving the specialized interprofessional team approach would show an increase in health-related quality of life and function at 12 months, compared with those receiving usual home care. Further, we hypothesized that the intervention would pay for itself by reducing the use of expensive health care resources.

\section{Methods}

This randomized controlled trial was conducted in accordance with the Tri-Council Policy Statement, "Ethical Conduct for Research Involving Humans" "70. Ethics approval for the study was obtained from the Hamilton Health Sciences/ Faculty of Health Sciences Research Ethics Board and renewed yearly as required (\#05-408). All participants provided written informed consent for participation. The methods, results, and flow of participants through the study (Figure) are presented here according to the Consolidated Standards of Reporting Trials (CONSORT) Statement ${ }^{71}$. The study was conducted over a period of three years (October 1, 2005 to September 30, 2008).

\section{Research Questions}

The primary research question was: Does a 12-month specialized interprofessional team approach to stroke rehabilitation improve health-related quality of life and functioning among community-living stroke survivors using home care services, compared with usual home care services? The secondary research questions were: (1) does the intervention have a favourable effect on physical functioning, perceived social support, depressive and anxiety symptoms, number of strokes, cognitive function, and the level of community reintegration? (2) what are the 12-month costs of use of health services associated with the intervention?, and (3) which subgroups of community-living stroke survivors benefit most from the intervention?

\section{Participants and Setting}

This trial was a collaborative project between researchers in the McMaster University System-Linked Research Unit (SLRU) and decision-makers and front-line providers in the Toronto Central Community Care Access Centre (CCAC), Ontario Ministry of Health and Long-Term Care, Bridgepoint Health, Ontario Heart and Stroke Foundation, Greater Toronto Area (GTA) Rehabilitation Network, and five direct care provider agencies (Saint Elizabeth Health Care, Bridgepoint Health Community Rehab, Visiting Homemakers Association [VHA] Home HealthCare, Victorian Order of Nurses [VON], and Community Occupational Therapy Associates [COTA] Health) in Ontario, Canada.

Study participants had a confirmed diagnosis of stroke (firstever or recurrent) or transient ischemic attack (TIA) within the previous 18 months and were newly referred to (less than two weeks) and eligible for home care services through the Toronto Central CCAC, living in the community (not in an inpatient rehabilitation facility or long-term care), mentally competent to give informed consent (or with a substitute decision-maker available), and competent in English (or with an interpreter available). To validate their informed consent to enrolling and continued participation in the study, participants needed to score 5 or higher on the Short Portable Mental Status Questionnaire $(\text { SPMSQ })^{72}$ or have a substitute decision-maker to provide consent and complete the questionnaires on their behalf.

\section{Interventions}

Table 1 provides an overview of the specialized interprofessional team intervention compared with usual home care services.

\section{Control (Usual Home Care Services)}

Participants randomly allocated to the control group received standard home care services arranged by the CCAC. These included routine follow-up by the CCAC care coordinator whose focus was on assessing the client's eligibility for in-home health services, arranging and coordinating professional (e.g., nursing, occupational therapy, physiotherapy, social work, speechlanguage pathology, and nutrition) and non-professional home support services, providing information and referral to community agencies, and monitoring and evaluating the plan of care on an ongoing basis through in-home assessments ${ }^{73}$. Additional services may have included drug cards, supplies, equipment, transportation, and in-house laboratory services ${ }^{51}$. Clients could also arrange for private care for which they themselves paid. The CCAC care coordinator determined eligibility and priority level for home care services and the amount and type of home care services required, based on set criteria. Stroke survivor participants, their informal caregivers, and providers in the usual care group did not receive any component of the intervention protocol.

\section{Intervention (Specialized Interprofessional Team Approach)}

The intervention is described more fully elsewhere ${ }^{74}$. The intervention group was eligible for the same standard home care services as the control group, plus home visitation by a dedicated interprofessional team of healthcare providers (CCAC care coordinator (CC), registered nurse (RN), physiotherapist (PT), occupational therapist (OT), speech language pathologist (SLP), registered dietitian (RD), social worker (SW), and personal 


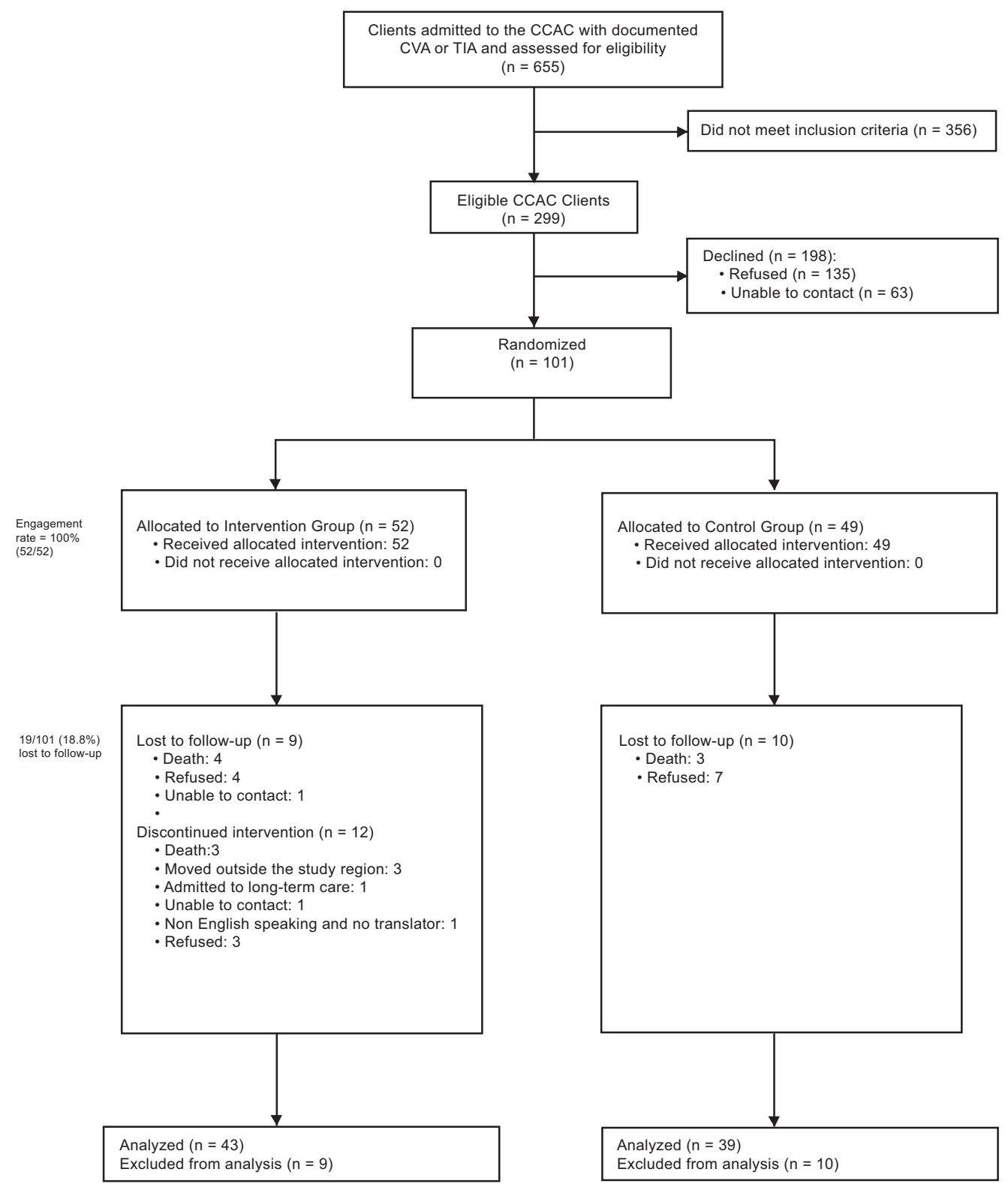

Figure: Study flow diagram. CVA: Cerebrovascular Accident; TIA: Transient Ischemic Attack

support worker (PSW)) over a 12-month period. The teams provided a comprehensive, collaborative, and evidence-based approach to stroke rehabilitation through regular home visits, standardized screening protocols, modification of risk factors for stroke, stroke education, caregiver support, referral and linkage to health and social services, monthly case conferencing, and development of a single evidence-based community reintegration plan. The intervention, which was individualized to the client's needs, was coordinated by the CCAC care coordinator. The aim of the specialized interprofessional team was to promote successful community reintegration, enhance health and quality of life, and reduce on-demand use of expensive health care services. All aspects of the intervention were developed through a collaborative process with decisionmakers and front-line providers with the goal of integrating the intervention into standard practice once the study ended.

Before implementation of the intervention, 30 interprofessional health care providers from six community agencies (Toronto Central CCAC and the five direct care provider agencies) completed a three-day training session conducted by the investigators using role-appropriate standardized training manuals and a manual for strengths-based practice. The training focused on the scope of the problem and effective strategies for stroke prevention, rehabilitation and promoting community reintegration. These training sessions were supplemented by additional sessions over the course of the trial. The care 
Table 1: Specialized interprofessional team approach to community-based stroke rehabilitation versus usual home care services

\begin{tabular}{|c|c|c|}
\hline Characteristics & Specialized Interprofessional Team & Usual Home Care \\
\hline Home Care Service Providers & $\begin{array}{l}\text { Dedicated interprofessional team of home care service } \\
\text { providers (CCAC care coordinator, registered nurse, } \\
\text { physiotherapist, occupational therapist, speech language } \\
\text { pathologist, registered dietitian, social worker, personal } \\
\text { support worker) with expertise in community-based stroke } \\
\text { prevention, rehabilitation and community reintegration }\end{array}$ & $\begin{array}{l}\text { No dedicated team of home care service providers with } \\
\text { expertise in stroke prevention, rehabilitation and community } \\
\text { reintegration }\end{array}$ \\
\hline Continuity of Care Provider & $\begin{array}{l}\text { Continuity of home care service provider through the use of a } \\
\text { dedicated team }\end{array}$ & Continuity of care provider not assured \\
\hline $\begin{array}{l}\text { Stroke Risk and Community Reintegration } \\
\text { Assessment Tools }\end{array}$ & $\begin{array}{l}\text { In-home assessment of factors that influence community } \\
\text { reintegration and stroke risk factors using standardized } \\
\text { assessment tools }\end{array}$ & No standardized assessment tools across disciplines \\
\hline $\begin{array}{l}\text { Stroke Prevention, Rehabilitation, and } \\
\text { Community Reintegration Strategies }\end{array}$ & $\begin{array}{l}\text { Implementation of evidence-based strategies for stroke } \\
\text { prevention, rehabilitation and community reintegration } \\
\text { including strategies for promoting behavioral change and } \\
\text { self-management }\end{array}$ & $\begin{array}{l}\text { No evidence-based practice standard for stroke prevention, } \\
\text { rehabilitation and community reintegration }\end{array}$ \\
\hline Access to Home Care Services & $\begin{array}{l}\text { Home care service enhancements: Structured and planned } \\
\text { home visits and access to care coordination over } 12 \text { months }\end{array}$ & $\begin{array}{l}\text { Delayed or minimal access to professional home care } \\
\text { services directed toward stroke prevention, rehabilitation } \\
\text { and community reintegration }\end{array}$ \\
\hline $\begin{array}{l}\text { Mechanisms for Team Communication and } \\
\text { Collaboration }\end{array}$ & $\begin{array}{l}\text { Regular information exchange among team members via } \\
\text { monthly case conferencing }\end{array}$ & $\begin{array}{l}\text { No case conferences and limited communication and } \\
\text { collaboration among team members }\end{array}$ \\
\hline Information Systems & $\begin{array}{l}\text { A single evidence-based community reintegration plan } \\
\text { among members of the interprofessional team }\end{array}$ & $\begin{array}{l}\text { No formal mechanisms for shared record keeping across } \\
\text { disciplines }\end{array}$ \\
\hline
\end{tabular}

coordinators met with the investigators monthly during the trial for ongoing coaching and supervision to enhance fidelity to treatment.

A stroke rehabilitation management protocol was developed to provide a systematic, standardized, and evidence-based approach to the identification and modification of factors that influence community reintegration across disciplines. The protocol included a summary of the dimensions of community reintegration, standardized screening tools, and evidence-based strategies to address these dimensions. The dimensions of community reintegration included health management, life roles, social network, environment, communication, mobility, caregiver support, and financial management ${ }^{7}$. The screening tools targeted factors that influence community reintegration, such as functional, mobility, and cognitive limitations; depression; and nutritional status. A stroke risk assessment tool was developed to identify and address risk factors for stroke e.g., hypertension, smoking, poor diet, obesity, physical inactivity ${ }^{6}$, using evidencebased management strategies.

Each stroke survivor was discussed by the interprofessional team at a case conference at least once per month for 12 months. A meeting record/progress report was used to systematically guide the team through a series of questions that triggered assessment of each dimension of community reengagement, stroke risk factors, use of strengths-based practice, and recommended actions for promoting successful community reengagement and stroke prevention for each study participant. Strengths-based practice is a directive client-centred counselling style that emphasizes people's self-determination, strengths and abilities, not their deficits, weaknesses or problems ${ }^{75,76}$. The overall goal of using strengths-based practice was to facilitate community reintegration by empowering and supporting individuals to develop goals and plans to achieve them, and enhance self-care and independence ${ }^{77}$.

The CCAC CC developed an evidence-based community reintegration plan to meet mutually agreed upon and attainable goals in collaboration with the client, the client's primary care physician, and the other members of the interprofessional team. The plan included specific short-term and 12-month goals, a list of actions and referrals, and a record of all recommend-ations. The CC liaised with the client's primary care physician and other providers to initiate referrals to a comprehensive range of services and supports to address individual client needs.

\section{Outcomes}

Independent interviewers, blinded to the purpose of the study and group assignment, assessed participants at baseline (prerandomization) and 12 months following randomization through a structured in-home interview lasting about one hour. The interviewers were experienced health professionals who underwent intensive training, standardization, and inter-rater reliability assessment in all interview and data collection procedures.

The primary measure of effect was the change in healthrelated quality of life and functioning from baseline to 12 months as measured by the Short Form (SF)-36 health survey ${ }^{78}$. Secondary measures of effect were changes in the following variables from baseline to 12 months: (i) physical functioning and related quality of life measured by the Stroke Impact Scale 16 (SIS-16) ${ }^{79}$, (ii) perceived social support measured by the Personal Resource Questionnaire (PRQ-85-Part 2) ${ }^{80}$, (iii) depressive symptoms measured by the Centre for Epidemiological Studies in Depression Scale (CES-D) ${ }^{81}$, (iv) 
anxiety and depressive symptoms measured by the Kessler-10 ${ }^{82}$, and (v) cognitive function measured by $\mathrm{SPMSQ}^{72}$. In addition, community reintegration at 12 months, measured by Reintegration to Normal Living Index (RNLI) ${ }^{83}$, and the number of strokes in the 12 months after randomization were recorded. All measurement tools have established reliability and validity. A detailed description of the measures can be found elsewhere ${ }^{74}$.

The costs of use of all types of health services from baseline to 12 months were determined using the Health and Social Services Utilization Inventory (HSSUI) ${ }^{84}$, which assesses costs from a societal perspective ${ }^{85}$. A societal perspective implies collecting all costs, regardless of who bears them. The wider the perspective taken, the more applicable the study is to social policy decisions ${ }^{85}$. The HSSUI consists of questions about the respondent's use of six categories of direct health care services: (1) primary care; (2) emergency department and specialists; (3) hospital days; (4) seven types of other health and social professionals; (5) medications; and (6) lab services. Inquiries were restricted to the reliable duration of recall: 12 months for remembering a hospitalization, six months for a visit to the physician, and four days for use of a prescription medication ${ }^{84}$. The 12-month cost data were derived from "quantity" data reported on the HSSUI and 2006 "price" data obtained by our team for the HSSUI that are reported in detail elsewhere ${ }^{84}$. The product of the number of units of service (quantity) and unit cost (price) is total cost. The six month estimate was multiplied by two to approximate the total health service utilization cost for the 12 month intervention period. This measure has been previously tested and assessed for reliability and validity ${ }^{86,87}$, and was recently acknowledged as one of the few published measures of ambulatory utilization that is empirically validated ${ }^{88}$. The costs of use of health services measured by the HSSUI included the program-specific costs.

\section{Sample Size}

The sample size was calculated to detect a clinically important difference of ten points in mean change in the SF-36 physical functioning score from baseline to 12 months. A sample size of 132 (66 per group) was estimated to be sufficient to address this primary outcome, including an allowance of an additional $20 \%$ to offset drop-outs (2-tailed alpha $=0.05$; beta $=$ $0.20)$. In the general population, a difference of this size would be associated with a $30 \%$ lower five year mortality rate and a $50 \%$ reduction in the proportion of people unable to work ${ }^{78}$.

\section{Randomization}

After participants provided written consent and completed baseline questionnaires, they were randomly assigned by the project coordinator at McMaster University to one of the two treatment strategies using a 1:1 allocation ratio. Randomization was achieved using consecutively numbered, sealed, opaque envelopes containing randomly generated numbers constructed by a biostatistician who was not involved in the recruitment process.

\section{Blinding}

Once randomization had taken place, the CCAC case managers, members of the interprofessional team, and participants were aware of group assignments. This lack of blinding was unavoidable. However, the outcome assessors and statistician/data analyst were blinded to the purpose of the study and group assignments.

\section{Statistical Methods}

All analyses were performed using SPSS version 16.0 for Windows on an intention-to-treat basis. The baseline characteristics of the sample were summarized using descriptive statistics expressed as mean (standard deviation [SD]) or median (minimum-maximum) for continuous variables and count (percent) for categorical variables. All statistical tests were performed using two-sided tests at the 0.05 level of significance. For all models, the results were expressed as effect (or odds ratios for binary outcomes), standard errors, corresponding twosided $95 \%$ confidence intervals $(\mathrm{CI})$, and associated p-values. The hypotheses of effectiveness and costs were tested in twogroup comparisons of all participants who completed the 12month follow-up, whether or not they received the intervention. We used repeated measures analysis of variance (ANOVA) or chi square test to compare the mean changes in scores or proportions for primary and secondary outcomes at 12 months. Data accuracy, assumptions of normality, and presence of outliers were assessed. Non-parametric tests (Kruskal-Wallis) were used if the normality assumption was seriously violated. Because cost data are often right skewed, non-parametric tests were used to evaluate differences in medians between the two groups. Adjusted analyses were performed using regression techniques to investigate the residual imbalance of key baseline characteristics on outcomes. Goodness-of-fit was assessed by examining the residuals for model assumptions and chi-square test of goodness-of-fit. It was anticipated that there would not be differential care/services between groups, except for the experimental intervention. However, all services for all study participants were monitored to identify any potential cointerventions. Because data was missing at the 12-month followup for $18.8 \%$ of the participants, we repeated the analyses using the Markov chain Monte Carlo multiple imputation procedure that assumes multivariate normality.

Subgroup analyses were performed by regression techniques using simple two-way interactions between study group and characteristics thought to influence physical functioning (sex, age, history of stroke, number of months post-stroke, depressive or anxiety symptoms, admission to acute care hospital in the last 12 months, $\geq 4$ comorbid health conditions, cognitive status, total number of home visits by trained CCAC providers, and access to informal support). The SF-36 physical functioning subscale score at 12 months was the dependent variable. We hypothesized that community-living stroke survivors with more risk factors would benefit most from the intervention. These subgroup analyses were decided a priori.

\section{RESULTS \\ Recruitment and Participant Flow}

Recruitment was conducted over an 18-month period between February 2006 and August 2007. A total of 655 consecutive CCAC clients with a confirmed diagnosis of stroke or TIA were screened for the study, and 299 (45.6\%) were 
considered eligible. In total, $101(33.8 \%)$ of the eligible home care clients consented and were randomized. Compared with consenters, more non-consenters were referred from an acute care hospital $(32.3 \%$ vs. $25.7 \%$; $\mathrm{p}<0.001)$ and were 75 years-ofage and older $(60.6 \%$ vs. $54.5 \% ; \mathrm{p}=0.33)$. Unfortunately, no data were available on other baseline characteristics of the 198 nonconsenters.

\section{Numbers Analyzed}

The proportion of stroke survivors who completed the study was $43 / 52(82.7 \%)$ in the intervention group and 39/49 $(79.6 \%)$ in the control group, or $81.2 \%$ overall (Figure). The results from multiple imputation were consistent with the results for the study completers for all of the outcomes (data not shown). Thus, the results were based on the 82 stroke survivors who completed the study.

The 19 drop-outs were similar to completers in most baseline characteristics, except that higher proportions of drop-outs were depressed, had more than two strokes, and had heart disease. Drop-outs had higher mean scores on the Kessler-10, indicating higher levels of depressive and anxiety symptoms, and lower mean scores in vitality and role functioning related to physical health. It appears that we retained in the study a somewhat higher-functioning group of stroke survivors than those who dropped out.

All participants randomized to the control group received some aspect of usual home care; information on duration of home care was not available. All participants randomized to the interprofessional team approach received some aspect of the intervention; they either had at least one home visit by a trained provider or were discussed at a team meeting. Twelve participants (including the nine who were lost to follow-up) discontinued the intervention early (Figure).

\section{Baseline Characteristics}

The two groups did not differ significantly for any baseline characteristic, but higher proportions of participants in the interprofessional group were female (51\% vs. 39\%) and $\geq 75$ years-of-age (61\% vs. 46\%). Compared with the usual care group, participants in the interprofessional group had lower mean scores in physical functioning and role functioning related to physical health, and higher mean scores in bodily pain that were clinically important ( $>5$ points difference) but not statistically significant. It is also noteworthy that participants in the interprofessional group showed a trend towards more days in hospital in the previous six months (42 vs. 33 days). It appears that the respondents in the interprofessional group were somewhat more disadvantaged than those in the usual care group. However, the use of analysis of covariance for these variables did not influence the statistical results (data not shown). Additional details on baseline characteristics by treatment group for the 82 stroke survivors who completed the study are shown in Tables 2 and 3.

\section{CCAC Services Received}

On average, participants in the interprofessional group who completed the study received 4.3 CCAC care coordinator visits, 29.1 nursing visits, 5.2 OT visits, 7.8 PT visits, 2.4 RD visits, 1 SW visits, 1.5 SLP visit, and 242 hours of care by a PSW over

Table 2: Comparison of selected demographic, clinical, and social characteristics between treatment groups at baseline (Study Completers, $n=82$ )*

\begin{tabular}{|c|c|c|c|c|}
\hline \multirow[t]{2}{*}{ Characteristic } & \multicolumn{2}{|c|}{$\begin{array}{l}\text { Interprofessional Group } \\
\qquad(n=43)\end{array}$} & \multicolumn{2}{|c|}{$\begin{array}{l}\text { Usual Care Group } \\
\qquad(n=39)\end{array}$} \\
\hline & $\mathbf{n}$ & $\%$ & $\mathbf{n}$ & $\%$ \\
\hline Male sex & 21 & $49 \%$ & 24 & $62 \%$ \\
\hline Married & 17 & $40 \%$ & 20 & $51 \%$ \\
\hline Living with others & 23 & $54 \%$ & 25 & $64 \%$ \\
\hline Access to informal support & 41 & $95 \%$ & 36 & $92 \%$ \\
\hline First stroke & 34 & $79 \%$ & 28 & $72 \%$ \\
\hline Time since stroke $\leq 6$ months & 30 & $70 \%$ & 27 & $69 \%$ \\
\hline 4 or more comorbid conditions & 15 & $35 \%$ & 14 & $36 \%$ \\
\hline 4 or more prescription medications & 37 & $86 \%$ & 33 & $85 \%$ \\
\hline Limited in activities of daily living & 37 & $86 \%$ & 34 & $90 \%$ \\
\hline Limited in bathing and dressing & 29 & $67 \%$ & 28 & $72 \%$ \\
\hline Limited in social activities & 30 & $70 \%$ & 30 & $77 \%$ \\
\hline Depressed (CES-D score $\geq 21$ ) & 12 & $28 \%$ & 13 & $33 \%$ \\
\hline \multirow[t]{2}{*}{ Cognitively impaired (SPMSQ score >4) } & 6 & $14 \%$ & 4 & $10 \%$ \\
\hline & Mean & SD & Mean & SD \\
\hline Age (years) & 75.8 & 12.4 & 70.6 & 14.5 \\
\hline
\end{tabular}

*No statistically significant difference between groups for any characteristic. SD: Standard Deviation 
Table 3: Group comparisons of questionnaire results at Baseline (Time 1) and 12-month follow-up (Time 2) (Study Completers, n=82)

\begin{tabular}{|c|c|c|c|c|c|c|}
\hline & \multicolumn{4}{|c|}{ Treatment Group } & \multicolumn{2}{|c|}{ Test Statistics } \\
\hline & \multicolumn{2}{|c|}{$\begin{array}{l}\text { Interprofessional } \\
\text { Group }(n=43)\end{array}$} & \multicolumn{2}{|c|}{$\begin{array}{l}\text { Usual Care Group } \\
\qquad(n=39)\end{array}$} & \multirow{2}{*}{$\begin{array}{c}\begin{array}{c}\text { Repeat } \\
\text { Measures } \\
\text { ANOVA }\end{array} \\
\text { T-test } \\
\text { p-values } \\
\end{array}$} & \multirow{2}{*}{$\begin{array}{l}\text { Difference in mean } \\
\text { change scores (T1-T2) } \\
(95 \% \mathrm{Cl})\end{array}$} \\
\hline & Mean & SD & Mean & SD & & \\
\hline \multicolumn{7}{|c|}{ SPMSQ Cognitive Status Score $(0-10)$} \\
\hline Time 1 & 2.38 & 2.11 & 2.23 & 2.37 & 0.76 & \multirow[b]{3}{*}{$-0.27(-110,0.53)$} \\
\hline Time 2 & 2.76 & 2.54 & 2.90 & 2.61 & 0.81 & \\
\hline Time 2 - Time 1 & 0.38 & 2.17 & 0.67 & 1.38 & 0.49 & \\
\hline \multicolumn{7}{|c|}{ CES-D Depression Score $(0-60)$} \\
\hline Time 1 & 14.16 & 11.59 & 14.74 & 9.96 & 0.81 & \multirow[b]{3}{*}{$-0.64(-4.79,3.51)$} \\
\hline Time 2 & 11.40 & 11.95 & 12.62 & 10.9 & 0.63 & \\
\hline Time 2 - Time 1 & -2.77 & 9.52 & -2.13 & 9.34 & 0.76 & \\
\hline \multicolumn{7}{|c|}{ Kessler-10 Score (10-50) } \\
\hline Time 1 & 18.94 & 8.02 & 19.03 & 6.18 & 0.95 & \multirow[b]{3}{*}{$-1.20(-3.41,1.02)$} \\
\hline Time 2 & 17.28 & 7.02 & 18.57 & 6.85 & 0.40 & \\
\hline Time 2 - Time 1 & -1.66 & 4.79 & -0.46 & 5.3 & 0.29 & \\
\hline \multicolumn{7}{|c|}{ SIS-16 Score (16-80) } \\
\hline Time 1 & 54.58 & 25.71 & 60.86 & 21.59 & 0.24 & \\
\hline Time 2 & 52.47 & 30.59 & 60.36 & 22.94 & 0.19 & \\
\hline Time 2 - Time 1 & -2.11 & 16.65 & -0.49 & 18.81 & 0.68 & $-1.61(-9.41,6.18)$ \\
\hline PRQ-85 Score ( & & & & & & \\
\hline Time 1 & 135.40 & 21.88 & 134.59 & 27.16 & 0.88 & \\
\hline Time 2 & 139.89 & 19.47 & 135.60 & 23.08 & 0.36 & \\
\hline Time 2 - Time 1 & 4.5 & 14.09 & 1.01 & 17.74 & 0.33 & $3.49(-3.52,10.50)$ \\
\hline SF-36 Physical & Score $(0-10$ & & & & & \\
\hline Time 1 & 26.94 & 27.23 & 32.82 & 25.20 & 0.32 & \\
\hline Time 2 & 28.84 & 30.68 & 28.85 & 28.48 & 1.00 & \\
\hline Time 2 - Time 1 & 1.9 & 21.64 & -3.97 & 23.2 & 0.24 & $5.87(-3.98,15.73)$ \\
\hline SF-36 Role-Phy & re $(0-100)$ & & & & & \\
\hline Time 1 & 28.39 & 30.58 & 36.46 & 28.18 & 0.22 & \\
\hline Time 2 & 47.14 & 35.22 & 50.33 & 28.21 & 0.66 & \\
\hline Time 2 - Time 1 & 18.75 & 33.03 & 13.87 & 29.33 & 0.49 & $4.88(-9.02,18.77)$ \\
\hline SF-36 Bodily $\mathrm{Pa}$ & $(0-100)$ & & & & & \\
\hline Time 1 & 64.72 & 30 & 58.77 & 30.15 & 0.37 & \\
\hline Time 2 & 65.70 & 31.02 & 60.28 & 27.52 & 0.41 & \\
\hline Time 2 - Time 1 & 0.98 & 24.53 & 1.51 & 33.42 & 0.93 & $-0.54(-13.34,12.27)$ \\
\hline SF-36 General H & ception Sco & e $(0-10 c$ & & & & \\
\hline Time 1 & 58.05 & 23.97 & 59.31 & 22.34 & 0.81 & \\
\hline Time 2 & 59.95 & 24.52 & 57.46 & 23.25 & 0.64 & \\
\hline Time 2 - Time 1 & 1.91 & 19.28 & -1.85 & 18.47 & 0.37 & $3.75(-4.56,12.07)$ \\
\hline SF-36 Vitality Sc & & & & & & \\
\hline Time 1 & 48.93 & 27.99 & 49.01 & 25.44 & 0.99 & \\
\hline Time 2 & 52.18 & 27.78 & 55.54 & 23.5 & 0.56 & \\
\hline Time 2 - Time 1 & 3.25 & 21.47 & 6.52 & 21.88 & 0.50 & $-3.28(-12.88,6.32)$ \\
\hline SF-36 Social Fu & Score $(0-10$ & & & & & \\
\hline Time 1 & 54.65 & 35.78 & 56.41 & 32.43 & 0.82 & \\
\hline Time 2 & 66.57 & 34.69 & 59.29 & 30.71 & 0.32 & \\
\hline Time 2 - Time 1 & 11.92 & 39.81 & 2.88 & 34.94 & 0.28 & $9.03(-7.50,25.57)$ \\
\hline SF-36 Role-Emo & ore $(0-100)$ & & & & & \\
\hline Time 1 & 71.12 & 34.47 & 68.42 & 31.43 & 0.72 & \\
\hline Time 2 & 81.59 & 27.85 & 76.10 & 27.34 & 0.37 & \\
\hline Time 2 - Time 1 & 10.47 & 33.59 & 7.68 & 31.8 & 0.70 & $2.79(-11.73,17.31)$ \\
\hline SF-36 Mental He & $e(0-100)$ & & & & & \\
\hline Time 1 & 72.56 & 22.08 & 69.29 & 21.28 & 0.50 & \\
\hline Time 2 & 77.41 & 19.81 & 75.00 & 16.26 & 0.55 & \\
\hline Time 2 - Time 1 & 4.85 & 19 & 5.71 & 17.93 & 0.84 & $-0.85(-8.99,7.29)$ \\
\hline SF-36 Physical I & mponent Su & nmary & core $(0-10$ & & & \\
\hline Time 1 & 42.44 & 21.95 & 46.18 & 19.34 & 0.42 & \\
\hline Time 2 & 48.29 & 23.23 & 47.81 & 18.96 & 0.92 & \\
\hline Time 2 - Time 1 & 5.85 & 15.88 & 1.63 & 17.13 & 0.25 & $4.22(-3.08,11.52)$ \\
\hline SF-36 Mental He & ponent Sum & nary Sc & re $(0-100)$ & & & \\
\hline Time 1 & 62.94 & 24.4 & 61.32 & 21.59 & 0.74 & \\
\hline Time 2 & 69.55 & 22.12 & 67.57 & 18.58 & 0.67 & \\
\hline Time 2 - Time 1 & 6.61 & 19.37 & 6.32 & 18.76 & 0.95 & $0.28(-8.24,8.81)$ \\
\hline RNLI Score (0-2 & & & & & & \\
\hline Time 2 & 14.84 & 5.71 & 15.44 & 5.29 & 0.63 & $-0.60(-3.03,1.83)$ \\
\hline
\end{tabular}

SD: Standard Deviation; CI: Confidence Interval the 12-month period. Participants in the usual care group received, on average, 1.1 CCAC care coordinator visits, 20.4 nursing visits, 5.3 OT visits, 4.3 PT visits, 0.4 RD visits, $0.4 \mathrm{SW}$ visits, and 1 SLP visits, and 169 hours of care by a PSW. Overall, the proportion of stroke survivors receiving professional home care services was higher in the interprofessional group than in the usual care group. For example, $86 \%$ of clients in the interprofessional group received nursing services, compared with $47 \%$ in the usual care group ( $p=0.06$ ). A total of $96 \%$ of clients in the interprofessional group received visits from a CCAC care coordinator, compared with only $57 \%$ in usual care $(\mathrm{p}<0.001)$. In addition, $29 \%$ of clients in the interprofessional group received dietitian services, compare with only $8 \%$ in usual care $(\mathrm{p}=0.04)$. Participants in the interprofessional group were discussed a median of 11 times at interprofessional team meetings (data not shown).

\section{Primary Outcome: Health-Related Quality of Life and Functioning}

From baseline to the 12-month follow-up, both groups improved in most SF-36 dimensions of health-related quality of life and functioning (Table 3). However, the interprofessional group improved more than the usual care group in five of the eight subscales. Although these differences were not statistically significant, the difference detected was clinically meaningful ( $\geq 5$ points) for two of the subscales: physical functioning and social functioning. The mean change in the physical functioning subscale score in the interprofessional group was 5.87 points greater than in the usual care group (CI -3.98 to 15.73). A five-point change is considered clinically important ${ }^{78}$, but because the study was powered to detect a ten-point difference between groups in the SF-36 physical functioning subscale, this difference was not statistically significant. Participants in the interprofessional group also improved more in the social functioning subscale score than the usual care group (difference 9.03, CI -7.50 to 26). Again, this clinically important difference did not translate into a statistically significant difference between groups because of the small sample size and limited power.

\section{Secondary Outcomes of Effectiveness}

Physical Functioning and Related Quality of Life

The SIS-16 mean score improved in the two groups combined by $2.3 \%$ (from 57.56 at 
baseline to 56.22 at 12 months). However, the change in the SIS16 mean score did not differ between groups at the 12-month follow-up $(\mathrm{p}=0.68)$ (Table 3).

\section{Number of Strokes at 12 Months}

Of the 82 participants who completed the study, $11(13.4 \%)$ reported a total of 17 strokes in the 12-months after randomization, including nine hospitalized strokes. The interprofessional and usual home care groups did not differ in the number of strokes ( $10 \mathrm{vs} .7, \mathrm{p}=0.68$ ). In addition, there was no difference between groups in the number of hospital admissions related to a stroke ( 5 vs. $4, p=0.86$ ) (data not shown).

\section{Community Reintegration}

There was no statistically significant difference in the RNLI mean score between groups at the 12-month follow-up $(\mathrm{p}=0.63)$ (Table 3 ). At the end of the study, all 82 participants were living at home in the community (not in an inpatient rehabilitation facility or long-term care).

\section{Perceived Social Support}

The PRQ-85 (Part 2) mean score improved in the two groups combined by $2.1 \%$ (from 135.0 at baseline to 137.9 at 12 months). However, the change in the PRQ-85 mean score did not differ between groups $(\mathrm{p}=0.33)$ (Table 3$)$.

\section{Depression}

At 12 months, the depressive symptom mean score decreased overall by $17.0 \%$ (from 14.44 to 11.98). This difference translated into a $9.5 \%$ absolute reduction from baseline in the proportion of stroke survivors with depressive symptoms $(\geq 21$ out of 60 on the CES-D) (from $30.5 \%$ to $21 \%$ ). The change in depressive symptom mean score did not differ statistically or clinically between the two groups $(\mathrm{p}=0.76)$ (Table 3$)$.

\section{Depression and Anxiety}

The level of anxiety and depressive symptoms decreased overall by $5.7 \%$ from baseline to the 12-month follow-up (from 18.98 to 17.89 ), with no statistically significant difference between groups $(\mathrm{p}=0.29)$ (Table 3$)$.

\section{Cognitive Function}

The mean cognitive function score increased overall by $22.5 \%$ (from 2.31 to 2.83 ). This translated into an $11 \%$ increase from baseline in the proportion of clients with cognitive impairment ( $>4$ out of 10 on the SPMSQ). The change in cognitive function mean score did not differ between groups $(\mathrm{p}=0.49)$ (Table 3).

\section{Costs of Use of Health Services}

The mean 12-month costs of use of all types of health services (including the program-specific costs) decreased overall by $77.3 \%$ (from $\$ 85,986$ at baseline to $\$ 19,486$ at 12 -months). At 12-months, there was a higher total per-person mean costs of use of health services in the intervention group compared to usual home care although the difference was not statistically significant (difference $\$ 2,750, \mathrm{p}=0.76$ ). One extreme outlier was identified in the usual home care group. The single cost of use of nursing services for this usual home care participant fell well outside the range of costs of use of nursing services. The extreme outlier was removed from the visiting nursing data set and the mean difference between the groups was recalculated. The interprofessional group had higher mean per-person costs of use of nursing $(p=0.02)$. Although there was no statistically significant difference between groups in cost for any other individual health service, including acute hospitalization for stroke, use of long-term care or inpatient rehabilitation, the interprofessional group had higher per-person costs for physiotherapists, occupational therapists, social workers, dietitians, speech language pathologists, personal support worker, family physician, ambulance services, meals on wheels, and supplies or aids. These increases in costs was offset by lower per-person costs for prescription medications, physician specialist, psychiatrists and scans compared with the usual home care group (Table 4).

\section{Subgroup Analyses}

The a priori hypothesis for evaluating differences in the SF36 physical functioning subscale score at the 12-month followup included examining characteristics thought to influence physical functioning post-stroke. The findings indicated that there was no particular subgroup of stroke survivors that benefited more from the interprofessional team approach versus usual home care services (data not shown).

\section{DISCUSSION}

The objective of the present study was to determine the effectiveness and costs of a one-year specialized interprofessional team approach to community-based stroke rehabilitation compared with usual home care services. To our knowledge, this is the first randomized controlled trial with an economic evaluation on this topic. This study is important because the majority $(70 \%)$ of the stroke survivors in the present sample were within their first six months post-stroke, a time when individuals with stroke have the potential to make the most significant gains ${ }^{89-91}$. The setting of this trial is also important because it represents the logical target for any initiative to improve the delivery of community-based stroke prevention and rehabilitation to optimize the health-related quality of life of community-living stroke survivors.

We found that a specialized interprofessional team approach to community-based stroke rehabilitation, proactively provided to a general population of stroke survivors using home care services, $70 \%$ of whom were within their first six months poststroke, $35 \%$ of whom suffered from four or more chronic health problems, and $70 \%$ of whom were limited in basic activities of daily living, produced clinically important improvements in health-related quality of life (physical functioning and social functioning). Notably, these improvements were achieved at no more cost to society as a whole, thus making the intervention highly feasible given its clinical benefits. Further research with larger sample sizes is needed to determine if this result was a chance finding. Although we did not directly measure the acceptability of the intervention, the high engagement rate 
Table 4: Group comparisons of selected 12-month costs of use of health services at Baseline and 12-month followup, from a societal perspective (Study Completers, $n=82$ )*

\begin{tabular}{|c|c|c|c|c|c|c|}
\hline & \multicolumn{2}{|c|}{ Interprofessional $(n=43)$} & \multicolumn{2}{|c|}{ Usual Home Care $(n=39)$} & \multicolumn{2}{|c|}{ Kruskal-Wallis Test } \\
\hline & Mean & SD & Mean & SD & $x^{2}$ & $p$-value \\
\hline \multicolumn{7}{|c|}{ Direct Costs } \\
\hline \multicolumn{7}{|c|}{ Family Physician } \\
\hline Time 1 & $\$ 306.17$ & $\$ 332.47$ & $\$ 217.36$ & $\$ 284.40$ & 2.06 & 0.15 \\
\hline Time 2 & $\$ 362.92$ & $\$ 373.91$ & $\$ 293.11$ & $\$ 210.32$ & 0.00 & 0.95 \\
\hline \multicolumn{7}{|c|}{ Physician Specialist } \\
\hline Time 1 & $\$ 219.34$ & $\$ 363.16$ & $\$ 175.01$ & $\$ 308.90$ & 0.69 & 0.41 \\
\hline Time 2 & $\$ 184.71$ & $\$ 303.22$ & $\$ 235.47$ & $\$ 432.52$ & 0.16 & 0.69 \\
\hline \multicolumn{7}{|c|}{ Emergency Room Visits } \\
\hline Time 1 & $\$ 501.21$ & $\$ 605.65$ & $\$ 333.87$ & $\$ 337.23$ & 0.90 & 0.34 \\
\hline Time 2 & $\$ 187.95$ & $\$ 342.69$ & $\$ 126.64$ & $\$ 340.84$ & 1.20 & 0.27 \\
\hline \multicolumn{7}{|c|}{ Ambulance Service } \\
\hline Time 1 & $\$ 424.19$ & $\$ 556.32$ & $\$ 123.08$ & $\$ 239.19$ & 9.10 & 0.00 \\
\hline Time 2 & $\$ 212.09$ & $\$ 448.11$ & $\$ 49.23$ & $\$ 147.53$ & 2.94 & 0.09 \\
\hline \multicolumn{7}{|c|}{ Physiotherapist } \\
\hline Time 1 & $\$ 823.91$ & $\$ 2,523.62$ & $\$ 1,281.01$ & $\$ 2,705.44$ & 1.73 & 0.19 \\
\hline Time 2 & $\$ 2,248.31$ & $\$ 4,397.63$ & $\$ 1,930.33$ & $\$ 3,818.10$ & 0.01 & 0.92 \\
\hline \multicolumn{7}{|c|}{ Psychiatrist } \\
\hline Time 1 & $\$ 9.04$ & $\$ 43.74$ & $\$ 53.14$ & $\$ 253.38$ & 0.38 & 0.54 \\
\hline Time 2 & $\$ 9.04$ & $\$ 33.39$ & $\$ 119.56$ & $\$ 541.73$ & 1.78 & 0.18 \\
\hline \multicolumn{7}{|c|}{ Occupational Therapist } \\
\hline Time 1 & $\$ 277.81$ & $\$ 639.62$ & $\$ 480.66$ & $\$ 981.22$ & 0.01 & 0.91 \\
\hline Time 2 & $\$ 384.66$ & $\$ 1,495.09$ & $\$ 292.16$ & $\$ 1,054.66$ & 2.07 & 0.15 \\
\hline \multicolumn{7}{|c|}{ Speech Language Pathologist } \\
\hline Time 1 & $\$ 28.34$ & $\$ 104.72$ & $\$ 161.45$ & $\$ 502.27$ & 1.50 & 0.22 \\
\hline Time 2 & $\$ 269.25$ & $\$ 877.27$ & $\$ 168.62$ & $\$ 858.63$ & 0.81 & 0.37 \\
\hline \multicolumn{7}{|c|}{ Social Worker } \\
\hline Time 1 & $\$ 33.00$ & $\$ 98.23$ & $\$ 114.37$ & $\$ 433.32$ & 0.06 & 0.81 \\
\hline Time 2 & $\$ 193.31$ & $\$ 530.81$ & $\$ 62.38$ & $\$ 218.92$ & 1.70 & 0.19 \\
\hline \multicolumn{7}{|c|}{ Dietitian } \\
\hline Time 1 & $\$ 12.49$ & $\$ 49.17$ & $\$ 0.00$ & $\$ 0.00$ & 2.79 & 0.10 \\
\hline Time 2 & $\$ 134.32$ & $\$ 544.43$ & $\$ 79.21$ & $\$ 306.17$ & 0.54 & 0.46 \\
\hline \multicolumn{7}{|c|}{ Visiting Nurse } \\
\hline Time 1 & $\$ 107.74$ & $\$ 416.32$ & $\$ 201.95$ & $\$ 725.53$ & 1.31 & 0.25 \\
\hline Time 2 & $\$ 587.36$ & $\$ 1,037.43$ & $\$ 373.02$ & $\$ 1,010.24$ & 5.09 & 0.02 \\
\hline \multicolumn{7}{|c|}{ Personal Support Worker } \\
\hline Time 1 & $\$ 4,348.28$ & $\$ 11,911.57$ & $\$ 4,428.71$ & $\$ 18,235.63$ & 0.16 & 0.69 \\
\hline Time 2 & $\$ 6,343.79$ & $\$ 12,495.99$ & $\$ 4,632.94$ & $\$ 14,065.23$ & 2.36 & 0.12 \\
\hline \multicolumn{7}{|c|}{ Meals on Wheels } \\
\hline Time 1 & $\$ 21.96$ & $\$ 98.08$ & $\$ 32.90$ & $\$ 199.01$ & 1.05 & 0.31 \\
\hline Time 2 & $\$ 117.55$ & $\$ 375.07$ & $\$ 40.00$ & $\$ 249.8$ & 2.29 & 0.13 \\
\hline \multicolumn{7}{|c|}{ Other Health Professionals } \\
\hline Time 1 & $\$ 161.89$ & $\$ 721.77$ & $\$ 105.64$ & $\$ 398.79$ & 0.01 & 0.93 \\
\hline Time 2 & $\$ 437.99$ & $\$ 1,070.23$ & $\$ 604.41$ & $\$ 1,757.85$ & 1.03 & 0.31 \\
\hline
\end{tabular}


Table 4: continued

\begin{tabular}{|c|c|c|c|c|c|c|}
\hline & \multicolumn{2}{|c|}{ Interprofessional $(n=43)$} & \multicolumn{2}{|c|}{ Usual Home Care $(n=39)$} & \multicolumn{2}{|c|}{ Kruskal-Wallis Test } \\
\hline & Mean & SD & Mean & SD & $x^{2}$ & $p$-value \\
\hline \multicolumn{7}{|c|}{ Direct Costs } \\
\hline \multicolumn{7}{|c|}{ Outpatient Tests } \\
\hline Time 1 & $\$ 317.7$ & 458.48 & $\$ 285.97$ & $\$ 538.59$ & 0.11 & 0.75 \\
\hline Time 2 & $\$ 402.73$ & 557.76 & $\$ 446.96$ & $\$ 465.42$ & 0.89 & 0.35 \\
\hline \multicolumn{7}{|c|}{ a. Blood } \\
\hline Time 1 & $\$ 151.59$ & $\$ 215.39$ & $\$ 130.73$ & $\$ 276.80$ & 0.57 & 0.45 \\
\hline Time 2 & $\$ 258.16$ & $\$ 431.57$ & $\$ 239.96$ & $\$ 332.39$ & 0.28 & 0.60 \\
\hline \multicolumn{7}{|c|}{ b. Specimens } \\
\hline Time 1 & $\$ 25.27$ & $\$ 62.91$ & $\$ 13.53$ & $\$ 37.54$ & 0.43 & 0.51 \\
\hline Time 2 & $\$ 26.71$ & $\$ 40.97$ & $\$ 29.45$ & $\$ 48.79$ & 0.00 & 0.99 \\
\hline \multicolumn{7}{|c|}{ c. X-rays } \\
\hline Time 1 & $\$ 6.79$ & $\$ 79.48$ & $\$ 23.18$ & $\$ 57.72$ & 0.22 & 0.64 \\
\hline Time 2 & $\$ 29.79$ & $\$ 96.06$ & $\$ 27.05$ & $\$ 50.35$ & 0.33 & 0.57 \\
\hline \multicolumn{7}{|c|}{ d. Scans } \\
\hline Time 1 & $\$ 38.18$ & $\$ 93.84$ & $\$ 32.74$ & $\$ 70.91$ & 0.01 & 0.92 \\
\hline Time 2 & $\$ 3.93$ & $\$ 82.11$ & $\$ 88.86$ & $\$ 150.13$ & 2.98 & 0.08 \\
\hline \multicolumn{7}{|c|}{ Prescription Medications } \\
\hline Time 1 & $\$ 2,915.71$ & $\$ 1,867.37$ & $\$ 2,494.07$ & $\$ 1,579.17$ & 0.74 & 0.39 \\
\hline Time 2 & $\$ 2,998.44$ & $\$ 2,342.62$ & $\$ 3,255.17$ & $\$ 3,593.44$ & 0.01 & 0.92 \\
\hline \multicolumn{7}{|c|}{ Supplies, Aids or Devices } \\
\hline Time 1 & $\$ 2,109.32$ & $\$ 3,290.06$ & $\$ 653.98$ & $\$ 1,859.86$ & 4.11 & 0.04 \\
\hline Time 2 & $\$ 2,229.74$ & $\$ 3,772.83$ & $\$ 1,316.44$ & $\$ 3,044.84$ & 3.04 & 0.08 \\
\hline \multicolumn{7}{|c|}{ Direct cost (excluding hospital) } \\
\hline Time 1 & $\$ 12,728.11$ & $\$ 14,189.20$ & $\$ 11,369.02$ & $\$ 18,453.86$ & 3.096 & 0.08 \\
\hline Time 2 & $\$ 17,375.22$ & $\$ 17,453.68$ & $\$ 14,123.29$ & $\$ 16,554.62$ & 0.69 & 0.41 \\
\hline \multicolumn{7}{|c|}{ Acute Care Hospital } \\
\hline Time 1 & $\$ 8,3472.15$ & $\$ 103,602.60$ & $\$ 63,355.59$ & $\$ 90,353.48$ & 0.99 & 0.32 \\
\hline Time 2 & $\$ 5,649.36$ & $\$ 19,399.04$ & $\$ 5,237.26$ & $\$ 22,415.87$ & 0.81 & 0.37 \\
\hline \multicolumn{7}{|c|}{ Direct Cost (including hospital) } \\
\hline Time 1 & $\$ 96,200.26$ & $\$ 104,620.20$ & $\$ 74,724.60$ & $\$ 89,005.09$ & 1.29 & 0.26 \\
\hline Time 2 & $\$ 20,794.84$ & $\$ 26,480.53$ & $\$ 18,044.11$ & $\$ 25,207.31$ & 0.10 & 0.76 \\
\hline \multicolumn{7}{|c|}{ Indirect Costs } \\
\hline \multicolumn{7}{|c|}{ Worker's Compensation } \\
\hline Time 1 & $\$ 85.12$ & $\$ 558.14$ & $\$ 0.00$ & $\$ 0.00$ & 0.91 & 0.34 \\
\hline Time 2 & $\$ 0.00$ & $\$ 0.00$ & $\$ 0.00$ & $\$ 0.00$ & 0.00 & 1.00 \\
\hline \multicolumn{7}{|c|}{ Old Age Security } \\
\hline Time 1 & $\$ 4,523.80$ & $\$ 3,089.82$ & $\$ 3,602.97$ & $\$ 3,913.66$ & 1.74 & 0.19 \\
\hline Time 2 & $\$ 4,743.9$ & $\$ 3,455.53$ & $\$ 4,361.88$ & $\$ 4,358.54$ & 0.57 & 0.45 \\
\hline \multicolumn{7}{|c|}{ Disability Pension } \\
\hline Time 1 & $\$ 0.00$ & $\$ 0.00$ & $\$ 142.75$ & $\$ 891.50$ & 1.10 & 0.29 \\
\hline Time 2 & $\$ 0.00$ & $\$ 0.00$ & $\$ 800.00$ & $\$ 4,996.00$ & 1.10 & 0.29 \\
\hline \multicolumn{7}{|c|}{ Ontario Disability Support Program } \\
\hline Time 1 & $\$ 118.79$ & $\$ 633.95$ & $\$ 1,913.85$ & $\$ 5,928.90$ & 1.98 & 0.16 \\
\hline Time 2 & $\$ 138.14$ & $\$ 678.76$ & $\$ 398.46$ & $\$ 1,989.05$ & 0.09 & 0.76 \\
\hline
\end{tabular}


Table 4: continued

\begin{tabular}{|c|c|c|c|c|c|c|}
\hline & \multicolumn{2}{|c|}{ Interprofessional $(n=43)$} & \multicolumn{2}{|c|}{ Usual Home Care $(n=39)$} & \multicolumn{2}{|c|}{ Kruskal-Wallis Test } \\
\hline & Mean & SD & Mean & SD & $x^{2}$ & $p$-value \\
\hline \multicolumn{7}{|c|}{ Indirect Costs } \\
\hline \multicolumn{7}{|c|}{ Canada Pension } \\
\hline Time 1 & $\$ 4,512.86$ & $\$ 4,453.63$ & $\$ 3,839.1$ & $\$ 4,110.21$ & 0.78 & 0.38 \\
\hline Time 2 & $\$ 4,287.84$ & $\$ 4,331.20$ & $\$ 4,682.63$ & $\$ 4,816.08$ & 0.10 & 0.76 \\
\hline \multicolumn{7}{|c|}{ Canada Pension, Disability } \\
\hline Time 1 & $\$ 435.27$ & $\$ 1,803.35$ & $\$ 323.38$ & $\$ 2,019.54$ & 0.78 & 0.38 \\
\hline Time 2 & $\$ 850.88$ & $\$ 2,466.48$ & $\$ 815.82$ & $\$ 2,911.08$ & 0.61 & 0.44 \\
\hline \multicolumn{7}{|l|}{ GAINS } \\
\hline Time 1 & $\$ 11.16$ & $\$ 73.20$ & $\$ 330.15$ & $\$ 1,917.50$ & 0.49 & 0.48 \\
\hline Time 2 & $\$ 3.35$ & $\$ 21.96$ & $\$ 82.18$ & $\$ 513.19$ & 0.01 & 0.93 \\
\hline \multicolumn{7}{|c|}{ Veteran's Pension } \\
\hline Time 1 & $\$ 390.70$ & $\$ 2,561.98$ & $\$ 0.00$ & $\$ 0.00$ & 0.91 & 0.34 \\
\hline Time 2 & $\$ 251.16$ & $\$ 1,646.98$ & $\$ 12.00$ & $\$ 74.94$ & 0.00 & 0.96 \\
\hline \multicolumn{7}{|c|}{ Survivor's Benefits } \\
\hline Time 1 & $\$ 195.35$ & $\$ 1,280.99$ & $\$ 90.40$ & $\$ 564.55$ & 0.00 & 0.96 \\
\hline Time 2 & $\$ 0.00$ & $\$ 0.00$ & $\$ 0.00$ & $\$ 0.00$ & 0.00 & 1.00 \\
\hline \multicolumn{7}{|c|}{ Employment Insurance } \\
\hline Time 1 & $\$ 0.00$ & $\$ 0.00$ & $\$ 125.13$ & $\$ 595.15$ & 2.23 & 0.14 \\
\hline Time 2 & $\$ 0.00$ & $\$ 0.00$ & $\$ 208.21$ & $\$ 1,300.24$ & 1.10 & 0.29 \\
\hline \multicolumn{7}{|l|}{ Welfare } \\
\hline Time 1 & $\$ 0.00$ & $\$ 0.00$ & $\$ 30.77$ & $\$ 192.15$ & 1.10 & 0.29 \\
\hline Time 2 & $\$ 0.00$ & $\$ 0.00$ & $\$ 196.92$ & $\$ 1,229.78$ & 1.10 & 0.29 \\
\hline \multicolumn{7}{|c|}{ Other Government Cheques } \\
\hline Time 1 & $\$ 183.26$ & $\$ 867.02$ & $\$ 300.92$ & $\$ 1,347.36$ & 0.73 & 0.39 \\
\hline Time 2 & $\$ 242.72$ & $\$ 922.11$ & $\$ 381.74$ & $\$ 2,148.61$ & 0.60 & 0.44 \\
\hline \multicolumn{7}{|c|}{ Private Insurance } \\
\hline Time 1 & $\$ 1,897.31$ & $\$ 6,005.93$ & $\$ 2,393.45$ & $\$ 10,167.82$ & 0.99 & 0.32 \\
\hline Time 2 & $\$ 1,479.07$ & $\$ 5,924.31$ & $\$ 953.85$ & $\$ 5,762.76$ & 0.53 & 0.47 \\
\hline \multicolumn{7}{|c|}{ Cash Transfer Cost } \\
\hline Time 1 & $\$ 12,353.62$ & $\$ 7,662.84$ & $\$ 13,092.88$ & $\$ 10,269.32$ & 0.06 & 0.81 \\
\hline Time 2 & $\$ 11,997.06$ & $\$ 6,842.61$ & $\$ 12,893.68$ & $\$ 6,995.23$ & 0.91 & 0.34 \\
\hline
\end{tabular}

M: Mean; SD: Standard Deviation

(94.2\%) and relatively low dropout rate $(18.8 \%)$ over the 12 month study period suggests that this approach is highly acceptable to this population. This study demonstrates that, with modest reorganization of the delivery of existing home care services, giving greater priority to specialized interprofessional teams, prevention, and rehabilitation, meaningful enhancements in quality of life can result.

The results of our study add to the growing evidence for the effectiveness of a specialized interprofessional team approach to community-based stroke rehabilitation in producing clinically important improvements in two dimensions of health-related quality of life (physical functioning and social functioning) $28,29,38-40$. However, the stroke survivors recruited into this study differ from those commonly included in other community-based trials because we included people with any level of stroke severity, cognitive impairment, and other comorbidities. Such people are often excluded from community-based studies. Thus, this study makes an important contribution by providing 
knowledge of the effectiveness of an interprofessional team approach among a more disabled group of stroke survivors than recruited in previous studies.

After one year, compared with baseline, both groups improved in most SF-36 dimensions of health-related quality of life and functioning, suggesting that both approaches to care had a positive impact on health-related quality of life (Table 3). However, participants in the interprofessional group showed a trend towards greater improvement in SF-36 physical functioning scores than the usual home care participants. Given the lower level of physical functioning in the interprofessional group at baseline, this is a clinically important gain. Our findings are consistent with those of previous studies, which have reported significant improvements in physical functioning and independence with a specialized interprofessional approach $28,29,38-40$. This finding is noteworthy, given that reduced physical functioning is highly predictive of acute hospitalization, use of home care services ${ }^{67,92}$, falls ${ }^{93,94}$, and poorer community reintegration after stroke ${ }^{1}$.

As expected, improvements in physical functioning resulted in a clinically important improvement in social functioning for participants in the interprofessional group compared to those in usual care. This finding concurs with those found in another ESD trial $^{28}$. This study from Canada found that by three months after stroke, patients receiving early supported discharge from an interprofessional team scored higher on the SF-36 social functioning subscale than the usual care group. These improvements are noteworthy given that the stroke survivors in the present sample reported significantly lower levels of physical and social functioning at baseline, compared with the general population of community-living stroke survivors ${ }^{1,12,95}$.

The observed trends towards improvements in health-related quality of life may be due to the fact that the interprofessional group received more professional home care services than the usual care group. For example, $86 \%$ of the stroke survivors in the interprofessional group received nursing services, compared with only $47 \%$ in the usual care group. However, there was no interaction between the number of home visits and the change in the SF-36 physical functioning subscale score between study groups. Therefore, we conclude that it is the "quality", not the "quantity" of visits that made the difference. Research has indicated that the perception of support may have a stronger influence on specific health outcomes than the enactment of support ${ }^{96}$. Nevertheless, the present study showed that an interprofessional approach had a positive effect on two important dimensions of health-related quality of life - physical and social functioning, both of which are integral aspects of community reintegration after stroke ${ }^{1,95,97}$. In addition, research has shown that there is a relationship between the stroke survivor's functional status and the caregiver's quality of life ${ }^{98}$.

The finding that there was no difference between groups in the level of community reintegration or the reduction in depressive symptoms was not consistent with current literature. Mayo et al reported higher levels of community reintegration with a specialized interprofessional approach to communitybased rehabilitation in the early discharge phase ${ }^{28}$. Bautz-Holter et al found that an interprofessional ESD intervention had a positive effect on mood at three months, but not at six months following discharge from hospital ${ }^{38}$. Although the prevalence of depressive symptoms decreased at the same rate in both groups over the course of the trial, it still remained high (21\%) at the one-year follow-up. One explanation for this finding is poor compliance with the intervention protocol by health care providers. Although the interprofessional team used a standardized tool to screen for depressive symptoms, goals related to mood or emotional status were identified for only $11.5 \%$ of the group. This finding suggests that use of a standardized screening tool for depressive symptoms had limited influence on clinician behaviour. Problems related to emotional and behavioural disturbances (e.g., depression) are often less readily recognized and addressed by professionals than those associated with physical aspects of care ${ }^{21}$. Further research is needed to understand the role of routinely administered instruments in clinical practice and the reasons why this approach is either used or ignored by clinicians ${ }^{99}$. Future trials are also needed that place more emphasis on strategies to increase the prevention, detection, and management of depression in this population. It is also possible that inconsistency in implementation of this aspect of the intervention was associated with variability in the participants' response to treatment.

Sampling bias may have influenced the results of the trial, because the clients who volunteered to participate might have been more likely to be receptive to the intervention. The data support this notion, in that there were improvements over time in both groups on most study variables. The simple passage of time or regression to the mean could also explain why most aspects of health-related quality of life and functioning, community reintegration, depressive symptoms, cognitive function, and perception of social support improved for all participants. Finally, it is also plausible that demonstrating differences in these outcomes requires a longer-follow-up period or a more intensive dose of the intervention. However, we could not establish if any of these factors were operating in our study.

\section{Implications}

The results of this project suggest that an integrated team approach to community-based stroke rehabilitation has a positive effect on health outcomes by fostering interprofessional teamwork and cross-disciplinary approaches that address a broad range of conditions (including psychiatric) related to stroke recovery ${ }^{32,52}$. Our study adds to the accumulating evidence showing that high-functioning interprofessional teams - those that have the client at the centre, communicate easily and frequently, have shared objectives and clear roles and responsibilities, and conduct interdependent decision-making improve the health of individuals with chronic health conditions ${ }^{100-105}$. The greatest opportunity for recovery after a stroke is a system of well-organized rehabilitation ${ }^{52}$.

We hypothesized that the interprofessional team approach would pay for itself by reducing the use of expensive health care resources. Our cost analysis showed higher per-person costs of use of health services in the interprofessional group compared to usual home care although the difference was not statistically significant. Although this cost analysis of a specialized interprofessional team intervention did not demonstrate significant cost offset compared with usual care, given its positive effects on health outcomes, the intervention may 
represent an efficient approach to improving the quality of community-based stroke rehabilitation and health outcomes for stroke survivors and their unpaid caregivers. Home care policy makers, agencies, and funders should evaluate the potential of specialized interprofessional stroke rehabilitation teams as a means of promoting evidence-based practices and ensuring the best possible outcomes for community-living stroke survivors.

There was no particular subgroup of stroke survivors that benefited more from the interprofessional team approach. This finding adds to the accumulating evidence that regardless of age, chronic illness, circumstance, geographic setting, or specific interventions, early, proactive, and comprehensive care for people with chronic needs is both more effective and no more expensive in a system of national health insurance than providing services on a limited, reactive, and piecemeal basis $86,87,100,106-108$. The costs of the added intervention have the potential to pay for themselves in the same year. There have been only a small number of economic evaluation studies and systematic reviews on interprofessional community-based stroke rehabilitation done worldwide $18,37,42,109-113$. However, these studies have focused only on the use of institutional care and community services as measures of cost. In addition, only one study was completed within Canada's unique health care system $^{42}$. Hence, our study provides a first estimate of the costs of use of health services associated with a specialized interprofessional team approach to community-based rehabilitation from a societal perspective.

Home care providers are well positioned to play a major role in providing community-based stroke rehabilitation to stroke survivors. The study results support and extend the findings of meta-analyses of many randomized controlled trials and evidence-based practice guidelines for providing communitybased stroke rehabilitation to stroke survivors and their unpaid caregivers. An interprofessional team approach should provide early access to appropriate services; use a variety of strategies aimed at stroke prevention, care, and rehabilitation that are tailored to individual needs; include patient and family education; involve substantial realignment of roles and scopes of practice; provide intensive case management; formalize mechanisms for communication among health care providers; include regular follow-up using validated screening instruments and evidence-based practice guidelines; involve providers with stroke expertise; and provide referral to and coordination of community services ${ }^{23,53,55,56}$. The intervention may be attractive to home care organizations that prioritize improving adherence to evidence-based guidelines.

\section{Strengths and Limitations of the Study}

Although the randomized design and high rates of engagement (94.2\%) and follow-up (<20\% dropout) were major strengths of this study, several limitations need to be considered when examining the results of our study. Despite concerted efforts, we were only able to recruit and randomize $33.8 \%$ of eligible clients. Thus, our final sample size was smaller than anticipated and may not have been truly representative of community-living stroke survivors using home care services. However, we were unable to fully assess any potential nonresponse bias because we were only able to obtain very limited information from the people who refused to participate. Generally, this finding is in keeping with other ESD trials that reported recruiting only a minority (30\% to $45 \%$ ) of stroke survivors $^{27}$. Future research is warranted to identify the most effective strategies for recruiting community- living stroke survivors, specifically those who are older and are being discharged from an acute care hospital setting.

The process used to randomly assign eligible and consenting participants to treatment groups was not always acceptable to study participants. Participants often declined enrolment in the trial because they strongly favoured one of the two options and were aware they only had a 50\% chance of receiving it. Future studies in this population would benefit by using alternative randomization strategies that incorporate participants' preferences for treatment options ${ }^{114}$. It is also possible that loss to follow-up bias existed because the dropouts were a somewhat lower-functioning group than those who remained in the study. This fact may limit the generalizability of the results to lowerfunctioning stroke survivors, specifically those who have experienced two or more strokes. Although a proxy respondent played a critical role as a source of data for $15 \%$ of the study participants with limitations in cognition, physical health or language, it is possible that some results may have been over or underestimated $^{115}$.

Only the immediate 12-month effects of the intervention were observed. Further research is needed to determine if the effects of the intervention are sustained over longer periods of time. The finding of no statistically significant difference between groups in mean per-person costs of use of health services may be due to an insufficient sample size and limited power to detect differences in cost. The sample size calculation was based on measures of effectiveness and not the cost measures. Future trials with an economic evaluation are needed that have larger samples and sufficient power to detect costs differences.

Although the questionnaires were designed primarily to record outcomes, it is possible that their use might also have constituted an intervention in its own right. If the control participants benefited from these contacts, this minor intervention would have diluted the treatment effect and decreased the differences between groups.

An ongoing challenge of the research was the considerable turnover $(70 \%)$ of staff involved in providing the interprofessional team approach over the study period. This issue could have influenced the outcomes of our study. However, we were unable to ascertain how the staff turnover rate in the interprofessional approach compared to that in the usual home care group. Future research is needed to determine if staff turnover could have affected participation in the study and the study outcomes.

A limitation of this multifaceted trial is that we do not know exactly why or how the specialized interprofessional team approach works so well. It is unknown if it is the differing intensity and use of home care services, the differing training and skills of the providers, or the differing timing of the interventions that make the difference in outcomes. Lack of adherence (or compliance) by the participants to the intervention might have influenced the outcomes of our study. However, we 
could not establish whether this was the case. Future studies would benefit by focusing on the process of delivering care and include a quantitative measure of adherence, to identify the mechanism by which the intervention influences outcomes. Lastly, because this study took place in just one home care program in a well-developed urban region in Ontario, the results may not be representative of all stroke survivors, particularly those living in rural settings.

\section{Conclusions}

As the burden of stroke care in the community continues to increase with changing demographics and an increased focus on community-based rehabilitation, a shift in the way stroke care is delivered toward a more comprehensive, coordinated, and specialized approach becomes imperative. Home care has the potential to play a pivotal role in providing community-based stroke rehabilitation to further improve quality of life and reduce the effects of stroke, and promote community reintegration. Our study showed that a specialized interprofessional team approach to community-based stroke rehabilitation produced greater improvements in two important dimensions of health-related quality of life - physical and social functioning, compared to usual home care. Further research is warranted to identify the importance of these improvements from the client's perspective. Our cost analysis showed higher total per-person costs of use of health services in the interprofessional group compared to usual home care although the difference was not statistically significant. Although we were unable to demonstrate a significant cost offset with the interprofessional approach, given its positive impact on health outcomes and the feasibility and acceptability of this approach in the home care setting, the intervention may represent an efficient approach to improving the quality of community-based stroke rehabilitation and health outcomes for this population. Stroke produces devastating consequences and stroke survivors deserve this type of care but future research is needed to confirm the effects and costs of a specialized, interprofessional team approach to stroke rehabilitation. These studies should be conducted in different settings, include larger samples and a longer follow-up period, and investigate the mechanism by which the intervention influences outcomes.

\section{ACKNOWLEDGEMENTS}

The authors thank the 101 stroke survivors who participated in this study, as well as the home care providers from the Toronto Central Community Care Access Centre (CCAC), Saint Elizabeth Health Care, Bridgepoint Health Community Rehab, VHA Home HealthCare, VON, and COTA Health who provided the intervention. We also thank the interviewers and recruiters, who gave their full cooperation so that this challenging trial could be carried out. This study was supported by grants from the Canadian Institutes of Health Research (CIHR) Institute of Health Services and Policy Research, the CIHR Knowledge Translation Branch (Grant No.: 78692), and the Ontario Ministry of Health and Long-Term Care. Additional funding was provided by McMaster University System-Linked Research Unit, Toronto Central CCAC, Bridgepoint Health, Ontario Heart and Stroke Foundation, and GTA Rehabilitation Network. Maureen Markle-
Reid was supported by a Career Scientist Award from the Ontario Ministry of Health and Long-Term Care, Health Research Personnel Development Fund. We also thank the following individuals: Karen Auld (project coordinator), Rachel Cameron (administrative assistant), and Maria Wong (data analyst) from the McMaster University System-Linked Research Unit; and Kelly McCullagh (project support coordinator), Rosina Montemarano (project support coordinator), Catherine Ofosuah (decision support analyst) and Jonathon Chui (decision support analyst) from the Toronto Central CCAC.

\section{REFERENCES}

1. Mayo NE, Wood-Dauphinee S, Côté R, Durcan L, Carlton J. Activity, participation, and quality of life 6 months poststroke. Arch Phys Med Rehabil. 2002;83(8):1035-42.

2. Flick CL. Stroke rehabilitation. 4. Stroke outcome and psychosocial consequences. Arch Phys Med Rehabil. 1999;80(5 Suppl 1): S21-6.

3. Gresham GE, Duncan PW, Stason WB, et al. Post-stroke rehabilitation. Clinical practice guideline, No 16. Rockville, MD: U.S. Department of Health and Human Services. Public Health Service, Agency for Health Care Policy and Research; 1995 [cited 2009 Nov 27]. Available from: www.ncbi.nlm. nih.gov.

4. Health Canada. Economic burden of illness in Canada. Ottawa, Ontario: Health Canada; 1998 [cited 2009 Nov 27]. Available from: www.phac-aspc.gc.ca.

5. Heart and Stroke Foundation of Canada. The growing burden of heart disease and stroke in Canada. Ottawa, Ontario: Heart and Stroke Foundation of Canada; 2003 [cited 2009 Nov 27]. Available from: www.cvdinfobase.ca.

6. Heart and Stroke Foundation of Ontario. Stroke statistics. Toronto, Ontario: Heart and Stroke Foundation of Ontario; 2004 [cited 2009 Oct 14]. Available from: www.heartandstroke.ca.

7. Heart and Stroke Foundation of Ontario. Best practice guidelines for stroke care: community re-engagement. Toronto, Ontario: Heart and Stroke Foundation of Ontario; 2003 [cited 2009 Nov 27]. Available from: www.heartandstroke.on.ca.

8. Katzmarzyk PT. The Canadian obesity epidemic, 1985-1998. CMAJ. 2002;166(8): 1039-40.

9. Young J, Forster A. Review of stroke rehabilitation. BMJ. 2007;334 (7584):86-90.

10. Han B, Haley WE. Family caregiving for patients with stroke: review and analysis. Stroke. 1999;30(7):1478-85.

11. Hartman-Maeir A, Soroker N, Ring H, Avni N, Katz N. Activities, participation and satisfaction one-year post stroke. Disabil Rehabil. 2007;29(7):559-66.

12. Hopman WM, Verner J. Quality of life during and after inpatient stroke rehabilitation. Stroke. 2003;34(3):801-5.

13. Patel MD, Tilling K, Lawrence E, Rudd AG, Wolfe CD, McKevitt C. Relationships between long-term stroke disability, handicap and health-related quality of life. Age Ageing. 2006;35(3):273-9.

14. McKevitt C, Redfern J, Mold F, Wolfe C. Qualitative studies of stroke: a systematic review. Stroke. 2004;35(6):1499-505.

15. Hackett ML, Yapa C, Parag V, Anderson CS. Frequency of depression after stroke: a systematic review of observational studies. Stroke. 2005;36(6): 1330-40.

16. Young J, Murray J, Foster A. Review of longer-term problems after disabling stroke. Rev Clin Gerontol. 2003;13:55-65.

17. Ellis G, Stroke Liaison Workers Collaboration. Meta-analysis of stroke liaison workers for patients and carers: results by intervention characteristic. Cerebrovasc Dis. 2006;21(Suppl 4): 120.

18. Anderson C, Mhurchu CN, Brown PM, Carter K. Stroke rehabilitation services to accelerate hospital discharge and provide home-based care. Pharmacoeconomics. 2002;20(8): 537-52. 
19. Ciechanowski P, Wagner E, Schmaling K, et al. Communityintegrated home-based depression treatment in older adults: a randomized controlled trial. JAMA. 2004;291(13):1569-7.

20. Young J, Forster A. The Bradford community stroke trial: results at six months. BMJ. 1992;304(6834):1085-9.

21. White JH, Alston MK, Marqez JL, et al. Community-dwelling stroke survivors: function is not the whole story with quality of life. Arch Phys Med Rehabil. 2007;88(9):1140-6.

22. Dewey HM, Sherry LJ, Collier JM. Stroke rehabilitation 2007: what should it be? Int J Stroke. 2007;2(3):191-200

23. Stroke Unit Trialists' Collaboration. Organized inpatient (stroke unit) care for stroke. Cochrane Database Syst Rev. 2007;(4): CD000197.

24. Stroke Unit Trialists' Collaboration. A collaborative systematic review of the randomized trials of organized inpatient (stroke unit) care after first stroke. BMJ. 1997;314(7088):1151-9.

25. Stroke Unit Trialists' Collaboration. How do stroke units improve patient outcomes? A collaborative systematic review of the randomized trials. Stroke. 1997;28(11):2139-44.

26. Ronning OM, Gudvog B. Outcome of subacute rehabilitation: a randomized controlled trial. Stroke. 1998;29(4):779-84.

27. Early Supported Discharge Trialists. Services for reducing duration of hospital care for acute stroke patients. Cochrane Database Syst Rev. 2005;(2):CD000443.

28. Mayo N, Wood-Dauphinee S, Côté R, et al. There's no place like home: an evaluation of early supported discharge for stroke. Stroke. 2000;31(5):1016-23.

29. Indredavik B, Fjaertoft H, Ekeberg G, Løge AD, Mørch B. Benefit of an extended stroke unit service with early supported discharge: a randomized, controlled trial. Stroke. 2000;31(12): 2989-94.

30. Anderson C, Rubenach S, Mhurchu C, Clark M, Spencer C, Winsor A. Home or hospital for stroke rehabilitation? Results of a randomized controlled trial: I: health outcomes at 6 months. Stroke. 2000;31(5): 1024-31.

31. Langhorne P, Gillian T, Murray G, et al. Early supported discharge services for stroke patients: a meta-analysis of individual patients' data. Lancet. 2005;365(9458):501-6.

32. Teasell RW, Foley NC, Bhogal SK, Speechley MR. An evidencebased review of stroke rehabilitation. Top Stroke Rehabil. 2003; 10(1):29-58.

33. Larsen T, Olsen TS, Sorensen J. Early home-supported discharge of stroke patients: a health technology assessment. Int J Technol Assess Health Care. 2006;22(3):313-20.

34. Holmqvist L, Widen RPT, von Koch L, et al. A randomized controlled trial of rehabilitation at home after stroke in southwest Stockholm. Stroke. 1998;29(3):591-7.

35. Rudd AG, Wolfe CD, Tilling K, Beech R. Randomized controlled trial to evaluate early discharge scheme for patients with stroke. BMJ. 1997;315(1775):1039-44.

36. Rodgers H, Soutter J, Kaiser W, et al. Early supported discharge following acute stroke: pilot study results. Clin Rehabil. 1997; 11:280-7.

37. McNamee P, Chrjstensen J, Soutter J, et al. Cost analysis of early supported discharge for stroke. Age Ageing. 1998;27:345-51

38. Bautz-Holter E, Sveen U, Rygh J, Rodgers H, Wyller TB. Early supported discharge of patients with acute stroke: a randomized controlled trial. Disabil Rehabil. 2002;24(7):348-55.

39. Pessah-Rasmussen H, Wendel K. Early supported discharge after stroke and continued rehabilitation at home coordinated and delivered by a stroke unit in an urban area. J Rehabil Med. 2009;41(6):482-8

40. Fjaertoft H, Indredavik B, Lydersen S. Stroke unit care combined with early supported discharge: long-term follow-up of a randomized controlled trial. Stroke. 2003;34(11):2687-92.

41. Lincoln NB, Walker MF, Dixon A, Knights P. Evaluation of a multiprofessional community stroke team: a randomized control trial. Clin Rehabil. 2004;18(1):40-7.

42. Teng J, Mayo NE, Latimer E, et al. Costs and caregiver consequences of early supported discharge for stroke patients. Stroke. 2003;34(2):528-36.
43. Donnelly M, Power M, Russell M, Fullerton K. Randomized controlled trial of an early discharge rehabilitation service: the Belfast community stroke trial. Stroke. 2004;35(1):127-33.

44. Canadian Stroke Network, Heart and Stroke Foundation of Canada. Billions of dollars, tens of thousands of lives at stake - Why aren't proven stroke solutions being used consistently in Canada? Ottawa, Ontario: Canadian Stroke Network; 2006 [cited 2009 Nov 27]. Available from: www.canadianstroke strategy.ca.

45. Ontario Ministry of Health and Long-Term Care. Report of the joint stroke strategy working group. Toronto, Ontario: Ontario Ministry of Health and Long-Term Care; 2000 [cited 2009 Nov 27]. Available from: www.health.gov.on.ca.

46. Canadian Stroke Network. Stroke Canada Optimization of Rehabilitation by Evidence (SCORE) project. Ottawa, Ontario: Canadian Stroke Network; 2004 [cited 2010 Aug 1]. Available from: http://www.canadianstrokenetwork.ca/eng/tools/index.php.

47. Canadian Stroke Network. Integrated stroke care in Ontario: stroke evaluation report. Ottawa, Ontario: Canadian Stroke Network; 2006 [cited 2009 Nov 27]. Available from: www.canadianstroke strategy.ca.

48. Langhorne P. Editorial comment - Early supported discharge: an idea whose time has come? Stroke. 2003;34(11):2691-2.

49. Mayo NE, Nadeau L, Ahmed S, et al. Bridging the gap: the effectiveness of teaming a stroke coordinator with patient's personal physician on the outcome of stroke. Age Ageing. 2008; 37(1):32-8.

50. Hale LA. Community-based or home-based stroke rehabilitation: confusion or common sense? NZ J Physiother. 2004;32(3): $131-9$.

51. Canadian Home Care Association. Home care: the next essential service: meeting the needs of our aging population. Ottawa, Ontario: Canadian Home Care Association; 2008 [cited 2009 Nov 27]. Available from: www.cdnhomecare.ca.

52. Teasell RW, Foley NC, Salter K, Bhogal S, Jutai J, Speechley M. Evidence-based review of stroke rehabilitation 12th ed. [Internet]. London, Ontario; 2009 [cited 2009 Nov 27]. Available from: www.ebrsr.com.

53. Bayley M, Lindsay P, Hellings C, Woodbury E, Phillips S. Balancing evidence and opinion in stroke care: Canadian best practice recommendations for stroke care: summary. CMAJ. 2008;179 Suppl 12:S1-25.

54. Lindsay P, Bayley M, Hellings C, Hill M, Woodbury E, Phillips S. Canadian best practice recommendations for stroke care (updated 2008). CMAJ. 2008;179(12):S1-19.

55. Ostwald SK, Davis S, Hersch G, Kelley C, Godwin KM. Evidencebased educational guidelines for stroke survivors after discharge home. J Neurosc Nurs. 2008;40(3):173-91.

56. Strasser DC, Falconer JA, Stevens AB, et al. Team training and stroke rehabilitation outcomes: a cluster randomized trial. Arch Phys Med Rehabil. 2008;89(1):10-5

57. West GTA Stroke Network. Community stroke best practice guidelines. Toronto, Ontario: Heart and Stroke Foundation of Ontario; 2005 [cited 2009 Nov 27]. Available from: www.heart andstroke.on.ca.

58. Korner-Bitensky N, Wood-Dauphinee S, Teasell R, et al. Best versus actual practices in stroke rehabilitation: results of the Canadian National Survey. 6th World Stroke Congress. Stroke. 2006;37:631

59. Menon A, Korner-Bitensky N, Kastner M, McKibbon KA, Straus S. Strategies for rehabilitation professionals to move evidencebased knowledge into practice: a systematic review. J Rehabil Med. 2009;41:1024-32.

60. Lindsay P, Bayley M, McDonald A, Graham ID, Warner G, Phillips S. Toward a more effective approach to stroke: Canadian best practice recommendations for stroke care. CMAJ. 2008;178(11): 1418-25.

61. Anderson M, Parent K. Care in the home: public responsibilityprivate role. Kingston, Ontario: Queen's University, Department of Rehabilitation Medicine; 2000 [cited 2009 Nov 27]. Available from: www.utoronto.ca/hpme/dhr/pdf/Anderson_Parent.pdf. 
62. Canadian Home Care Association. Home care: a national health priority: visionary leadership can make it happen. Ottawa: Canadian Home Care Association; 2004.

63. Coyte PC, McKeever P. Home care in Canada: passing the buck. Can J Nurs Res. 2001;33(2):11-25.

64. Romanow RJ. Building on values: the future of health care in Canada - final report. National Library of Canada [Internet]. 2002 [cited 2009 Nov 27];8:171-86. Available from: publications.gc.ca.

65. Hollander MJ. Unfinished business: the case for chronic home care services, a policy paper. Victoria, BC: Hollander Analytical Services Ltd; 2003 [cited 2009 Nov 27]. Available from: www.ocsa.on.ca/userfiles/Hollander.pdf

66. Chappell N. Maintaining the integrity of home care. Healthcare Papers. 2000;1(4):91-5.

67. Markle-Reid M, Browne G, Weir R, Gafni A, Roberts J, Henderson S. Seniors at risk: the association between the six-month use of publicly funded home support services and quality of life and use of health services for older people. Can J Aging. 2008;27(2): 207-24.

68. Hall R, O'Callaghan C, Bayley M, et al. Ontario stroke evaluation report 2010: Technical report. Toronto: Institute for Clinical Evaluative Sciences; 2010.

69. Stroke Strategy Steering Committee, Heart and Stroke Foundation of Ontario. Stroke rehabilitation consensus panel report. Toronto, Ontario: Heart and Stroke Foundation of Ontario; 2000 [cited 2009 Nov 27]. Available from: http://profed heartand stroke.ca.

70. Canadian Institutes of Health Research, Natural Sciences and Engineering Research Council of Canada, Social Sciences and Humanities Research Council of Canada. Ethical conduct for research involving humans. Ottawa, Ontario: Interagency Secretariat on Research Ethics; 1998 (with 2000, 2002 and 2005 amendments) [cited 2009 Nov 27]. Available from: www.pre. ethics.gc.ca.

71. Moher D, Schulz KF, Altman D, CONSORT Group. The CONSORT Statement: revised recommendations for improving the quality of reports of parallel-group randomized trials. JAMA. 2001;285(15):1987-91.

72. Pfeiffer E. A short portable mental status questionnaire for the assessment of organic brain deficit in elderly patients. J Am Geriatr Soc. 1975;23(10):433-41.

73. MacAdam M. Home care: it's time for a Canadian model. Healthc Pap. 2000;1(4):9-36

74. Markle-Reid M, Orridge C, Weir R, et al. The comparative effects and costs of a specialized interprofessional team approach to community-based stroke rehabilitation for stroke survivors and their caregivers using home care services. Final Research Report Submitted to the Canadian Institutes of Health Research. 2009: October.

75. Rapp CA. The strengths model: case management for people suffering from severe and persistent mental illness. New York: Oxford University Press; 1998

76. Saleebey D. The strengths perspective in social work practice. 3rd ed. Toronto: Allyn and Bacon; 2002.

77. Heart and Stroke Foundation of Canada, Canadian Stroke Network. Towards a Canadian stroke strategy concept paper. Ottawa: The Foundation; 2003

78. Ware J E, Snow KK, Kosinski M, Gandek B. SF-36 health survey: manual and interpretation guide. Boston: The Health Institute, New England Medical Centre; 1993.

79. Duncan PW, Lai SM, Bode RK, Perera S, DeRosa J. Stroke Impact Scale-16: a brief assessment of physical function. Neurology. 2003;60(2):291-6.

80. Weinert C, Brandt P. Measuring social support with the Personal Resource Questionnaire. West J Nurs Res. 1987;9(4):589-602.

81. Radloff LS. The CES-D scale: a self-report depression scale for research in the general population. Appl Psych Meas. 1977;1: 385-401.

82. Kessler RC, Andrews G, Colpe LJ, et al. Short screening scales to monitor population prevalences and trends in non-specific psychological distress. Psychol Med. 2002;32(6):959-76.
83. Wood-Dauphinee SL, Opzoomer MA, Williams JI, Marchand B, Spitzer WO. Assessment of global function: the Reintegration to Normal Living Index. Arch Phys Med Rehabil. 1988;69(8): 583-90.

84. Browne G, Gafni A, Roberts J. Approach to the measurement of resource use and costs. (Working Paper S06-01). Hamilton, Ontario: McMaster University, System-Linked Research Unit on Health and Social Service Utilization; 2006

85. Drummond, MF, O'Brien B, Stoddart GL, Torrance GW. Methods for the economic evaluation of health care programmes. 2nd ed. Toronto: Oxford University Press; 1997.

86. Browne G, Roberts J, Byrne C, Gafni A, Weir R, Majumdar B. The costs and effects of addressing the needs of vulnerable populations: results of 10 years of research. Can J Nurs Res. 2001;33(1):65-76.

87. Browne G, Roberts J, Gafni A, et al. Economic evaluations of community-based care: lessons from twelve studies in Ontario. J Eval Clin Pract. 1999;5(4):367-85.

88. Guerriere DN, Ungar WJ, Corey M, et al. Evaluation of the ambulatory and home care record: agreement between selfreports and administrative data. Int $\mathrm{J}$ Technol Assess. 2006;22 (2):203-10.

89. Jorgensen HS, Nakayama H, Raaschou HO, Olsen TS. Stroke, neurologic and functional recovery the Copenhagen stroke study. Phys Med Rehabil Clin NA. 1999;10(4):887-906.

90. Horgan NF, O'Regan M, Cunningham CJ, Finn AM. Recovery after stroke: a 1-year profile. Disabil Rehabil. 2009;31(10):831-9.

91. Kelly-Hayes M, Wolf PA, Kase CS, Gresham GE, Kannel WB, D'Agostino RB. Time course of functional recovery after stroke: the Framingham study. J Neurol Rehabil. 1989;3(2):65-70.

92. Forbes DA, Stewart N, Morgan D, Anderson M, Parent K, Janzen B. Individual determinants of home-care nursing and housework assistance. Can J Nurs Res. 2003;35(4):14-36.

93. Markle-Reid M, Browne G, Gafni A, et al. A cross-sectional study of the prevalence, correlates, and costs of falls in older home care clients "at risk" for falling. Can J Aging. 2010;29(1):119-37.

94. Speechley M, Tinetti M. Falls and injuries in frail and vigorous community elderly persons. J Am Geriatr Soc. 1991;39(1): 46-52.

95. Clarke P, Marshall V, Black SE, Colantonio A. Well-being after stroke in Canadian seniors: findings from the Canadian study of health and aging. Stroke. 2002;33(4):1016-21.

96. Wetherington E, Kessler R. Perceived support, received support, and adjustment to stressful life events. J Health Soc Behav. 1986;27 (1):78-89.

97. Kim P, Warren S, Madill H, Hadley M. Quality of life of stroke survivors. Qual Life Res. 1999;8(4):293-301.

98. Jönsson AC, Lindgren I, Hallström B, Norrving B, Lindgren A. Determinants of quality of life in stroke survivors and their informal caregivers. Stroke. 2005;36(4):803-8.

99. Gilbody S, House AO, Sheldon TA. Screening and case finding instruments for depression. Cochrane Database Syst Rev. 2005; (4):CD002792

100. Markle-Reid M, Browne G, Gafni A, et al. The effects and costs of a multifactorial and interdisciplinary team approach to falls prevention for older home care clients "at risk" for falling: a randomized controlled trial. Can J Aging. 2010;29(1):139-61.

101. Barrett JV, Curran V, Glynn L, Godwin M. CHSRF synthesis: interprofessional collaboration and quality primary healthcare. Ottawa: Canadian Health Services Research Foundation; 2007 Dec [cited 2009 Nov 27]. Available from: www.chsrf.ca.

102. Sommers LS, Marton KI, Barbaccia JC, Randolph J. Physician, nurse, and social worker collaboration in primary care for chronically ill seniors. Arch Intern Med. 2000;160(12):1825-33.

103. Callahan CM, Boustani MA, Unverzagt FW, et al. Effectiveness of collaborative care for older adults with Alzheimer disease in primary care: a randomized controlled trial. JAMA. 2006;295 (18):2148-57.

104. Gilbody S, Bower P, Fletcher J, Richards D, Sutton AJ. Collaborative care for depression: a cumulative meta-analysis and review of longer-term outcomes. Arch Intern Med. 2006;166 (21):2314-21. 
105. McAlister FA, Lawson FME, Teo KK, Armstrong PW. A systematic review of randomized trials of disease management programs in heart failure. Am J Med. 2001;110(5):378-84.

106. Markle-Reid M, Weir R, Browne G, Roberts J, Gafni A, Henderson $S$. The effectiveness and efficiency of home-based nursing health promotion for older people: a review of the literature. Med Care Res Rev. 2006;63(5):531-69.

107. Williams AP, Challis D, Deber R, et al. Balancing institutional and community-based care: why some older persons can age successfully at home while others require residential long-term care. Longwoods Rev. 2009;7(1):95-105.

108. Markle-Reid M, Weir R, Browne G, Roberts J, Gafni A, Henderson $\mathrm{S}$. Health promotion for frail older home care clients. J Adv Nurs. 2006;54(3):381-95

109. Roderick P, Low J, Day R, et al. (2001). Stroke rehabilitation after hospital discharge: a randomized trial comparing domicillary and day-hospital care. Age Ageing. 2001;30(4):303-10.

110. Brady BK, McGahan L, Skidmore B. Systematic review of economic evidence on stroke rehabilitation services. Int J Tech Assess Health Care. 2005;21(1):15-21.
111. Anderson C, Mhurchu CN, Rubenach S, Clark M, Spencer C, Winsor A. Home or hospital for stroke rehabilitation? Results of a randomized controlled trial: II: cost minimization analysis at 6 months. Stroke. 2000;31(5):1032-7.

112. Beech R, Rudd A, Tilling K, Wolfe C. Economic consequences of early inpatient discharge to community-based rehabilitation for stroke in an inner-London teaching hospital. Stroke. 1999;30(4): 729-35.

113. von Koch L, de Pedro-Cuesta J, Kostulas V, Almazán J, Holmqvist LW. Randomized controlled trial of rehabilitation at home after stroke: one-year follow-up of patient outcome, resource use and cost. Cerebrovasc Dis. 2001;12:131-8.

114. Sidani S, Epstein DR, Moritz P. An alternative paradigm for clinical nursing research: an exemplar. Res Nurs Health. 2003;26(3): 244-55.

115. Neumann PJ, Araki SS, Gutterman, EM. The use of proxy respondents in studies of older adults: lessons, challenges, and opportunities. J Am Geriatr Soc. 2000;48(12):1646-54. 